Document downloaded from:

http://hdl.handle.net/10251/137616

This paper must be cited as:

Miguel-Tortola, L.; Miguel Sosa, P.; Pallarés Rubio, L. (2019). Strength of pile caps under eccentric loads: Experimental study and review of code provisions. Engineering Structures. 182:251-267. https://doi.org/10.1016/j.engstruct.2018.12.064

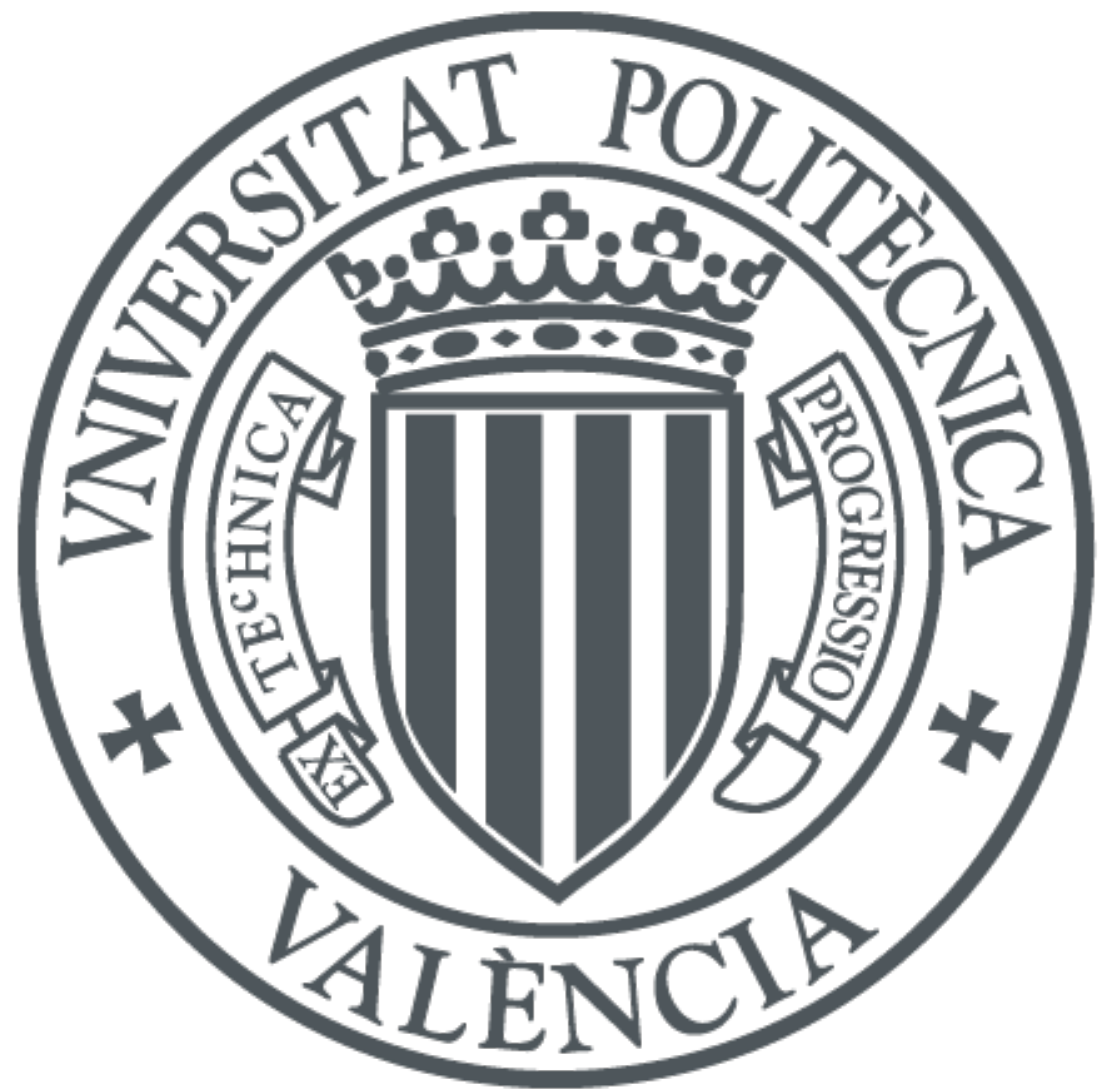

The final publication is available at

https://doi.org/10.1016/j.engstruct.2018.12.064

Copyright Elsevier

Additional Information 


\section{Strength of pile caps under eccentric loads: experimental study and review of code provisions}

4 Authors (Family name, Name)

5 Miguel-Tortola, Lucia a; Miguel, Pedro Francisco a*; Pallarés, Luis a

$6 \quad{ }^{*}$ Corresponding author: pmiguel@cst.upv.es

7 a Instituto de Ciencia y Tecnología del Hormigón (ICITECH), Universitat Politècnica de València, Camí de Vera, s/n, 46022 Valencia, Spain

9 Abstract

Pile caps are rigid reinforced concrete structures that transfer column loads, generally consisting of a

combination of an axial load and bending moments in one or two directions, to the piles. The design

formulations of pile caps for more than two piles were derived from the results of experimental tests under a centered load. The practice of checking both punching and shear failure modes is common as described in the literature review ${ }_{2}$ even thoughdespite these formulations were developed for more slender elements.

Currently, Codes ACI 318-14 and EC2 allow designing pile caps with strut-and-tie models or sectional approaches (shear, punching and flexural designs).

In this study, 21 full-scale pile caps with different shear span-depth ratios and reinforcement layouts

were studied to investigate the effect of eccentric loading on the strength and accuracy of the code

formulations. The results show that in eccentrically loaded pile caps, the ultimate load is reduced but the maximum pile reaction increases and the secondary reinforcement proves effective to enhance the pile cap strength.

Although the strut-and-tie models (STM) allow eccentric loads to be taken into consideration, they predict a much lower peak load than that observed at the experimental results and do not adequately reflect either the influence of slenderness or the failure mode.

In general the sectional approach provided by Codes ACI-318-14, EC2 and MC-2010 (Level I of Approximation) lead to safe predictions of the peak load but do not always correctly predict the failure mode. The ultimate load predicted by EC-2 formulation comes closest to the experimental peak load, accurately reflects the influence of slenderness and the effect of secondary reinforcement, however, additional assumptions need to be made for its application. The ACI formulation complemented by the CRSI- 
302008 Special Investigation for deep pile caps is the safest but does not adequately capture the effect of

31 horizontal and vertical secondary reinforcement. The MC2010 LoAI formulation is also conservative but

32 does not detect the influence of slenderness or the contribution of secondary reinforcement.

$34 \quad$ Notation

35 Latin upper case

$A_{s} \quad$ reinforcement area (generic)

$A_{s B} \quad$ main bunched reinforcement area

$A_{s H} \quad$ horizontal secondary reinforcement area

$A_{s V} \quad$ vertical secondary reinforcement area

$A_{s w} \quad$ punching shear reinforcement area

$E_{s} \quad$ modulus of elasticity of flexural and shear reinforcement

$J_{c} \quad$ property of assumed critical section analogous to polar moment of inertia

$M_{X} \quad$ bending moment around x-axis

$M_{y} \quad$ bending moment around y-axis

$N \quad$ axial force acting on column

$R_{i} \quad$ pile reaction (generic)

$R_{u, e} \quad$ experimental failure load on pile

$R_{y, B} \quad$ experimental yielding load of bunched reinforcement on pile

$R_{y, V} \quad$ experimental yielding load of stirrups on pile

$V_{E d} \quad$ punching shear force

$V_{\text {flex }} \quad$ flexural strength

$V_{\min } \quad$ minimum resistance predicted by the codes

$V_{o b s} \quad$ resistance predicted by the codes according to the observed mode of failure

$V_{R d, c} \quad$ punching shear resistance of concrete

${ }_{\triangle} V_{R d, \epsilon \underline{S}} \quad$ punching shear resistance provided by stirrups

$V_{R d, c s} \quad$ punching shear resistance of concrete and stirrups

$V_{S T M} \quad$ ultimate load predicted by STM

$V_{u, e} \quad$ experimental failure load on column

$V_{y, e} \quad$ experimental yielding load on column

$W_{1} \quad$ property of assumed critical section analogous to plastic section modulus

36

37 Latin lower case

$a_{V} \quad$ clear span; distance between column and pile edges

$b \quad$ effective breadth for shear

$b_{u} \quad$ diameter of a circle with the same surface as the region inside the basic control perimeter

$c \quad$ column diameter/side

$c_{A B} \quad$ length of the side of the equivalent rectangular control section, parallel to the bending axis

c1 long side of the column

$c_{2}$ short side of the column

$d \quad$ effective depth

$d_{g} \quad$ maximum size of aggregate 
level arm

39 Greek lower case

$\beta \quad$ coefficient of eccentricity

$\gamma_{c} \quad$ partial safety factor for concrete material properties

$\gamma_{s} \quad$ partial safety factor for the material properties of reinforcing steel

$\gamma_{V} \quad$ factor used to determine the fraction of bending moment transferred by eccentricity of shear at slab-column connections mid-depth strain in control section

factor defining the effective strength of concrete in a rectangular stress distribution inclination of the compressive stress field (struts)

modification factor to account for the properties of lightweight concrete

factor defining the height of the compression zone in a rectangular stress distribution Mean punching stress maximum shear force per unit length perpendicular to the basic control perimeter stress corresponding to nominal punching strength provided by concrete

$\nu_{R d, c^{*}} \quad$ stress corresponding to enhanced punching strength provided by concrete

$\nu_{R d, \max } \quad$ maximum punching shear resistance of concrete

$\rho_{l} \quad$ ratio of longitudinal tension reinforcement

$\sigma_{s w d} \quad$ stress activated in the shear reinforcement

$\varphi \quad$ diameter of steel reinforcement

$\phi \quad$ pile diameter

$\chi \quad$ enhancement factor of concrete strength

$\psi \quad$ slab rotation 
41

\section{Introduction}

Many building and bridge columns are founded on piles. Pile caps are rigid reinforced concrete structures that transfer column loads to the piles. Although these loads usually consist of a combination of an axial force and bending moments in one or two directions (Fig.1Fig. 1), all the experimental studies carried out to date that analysed pile cap behaviour have only considered centered loads. The first studies on these structural elements (Blévot ¥쁘 Fremy[1], Clarke [2], Sabnis and Gogate[3], Adebar[4]) set the standards for the design of pile caps based on strut-and-tie models (STM). Later studies (Suzuki et al [5-8], Bloodworth et al. [9], Gonsalves et. al [10], Delalibera and Giongo[11], Gu et al. [12]) experimentally analysed the influence of different design variables on pile cap behaviour. As some studies described brittle fracture due to punching shear, some authors (Adebar and Zhou [13] and (recently) Guo [14]) proposed methods based on checking the stresses in the bearing areas to limit the resistance of the pile caps due to this type of failure, while, Miguel-Tórtola et al. [15] recommended limiting punching stresses to avoid this problem on the basis of their own experimental studies on pile caps with three piles and a centered load. The first STM-based calculation method for pile caps under eccentric loads was proposed by Souza [16] but due to the lack of experimental studies on eccentric loads, the proposed model was verified by a non-linear FE analysis.

Another approach used in recent studies, such as those by Jensen \& Hoang [17]and Simões et al. [18], was to identify the failure mode from a kinematic formulation based on the Upper Bound Theorem of Plasticity.

Currently, Codes ACI 318-14 [19]and EC-2 (EN 1992-1-1) [20]allow pile caps to be designed by STM or by sectional approximations, applying the bending, shear and punching plate verifications. Both approaches require multiple hypotheses for their extension to these massive elements with markedly three-dimensional behaviour. Some design guides [21-23] offer recommendations for checking pile caps by STMs [24-26] or by the sectional methods of EC-2 or ACI 318-14, although no experimental validation has been carried out with an eccentric load on the column.

On the other hand, there is no agreement among the design codes about reinforcement recommendations for pile caps (Eurocode 2[20], EHE-08[, BS 5400-4:1990 y NBR 6118:2014[]. These codes differ in the bunched and distributed reinforcement ratios and the necessity of arranging stirrups tying the 
58 bunched bars. Vertical reinforcement was recommended by Leonhardt [] to sew the observed horizontal 99 crack due to the vertical tension force that may arise between piles when they are separated more than 0 three diameters

(a)

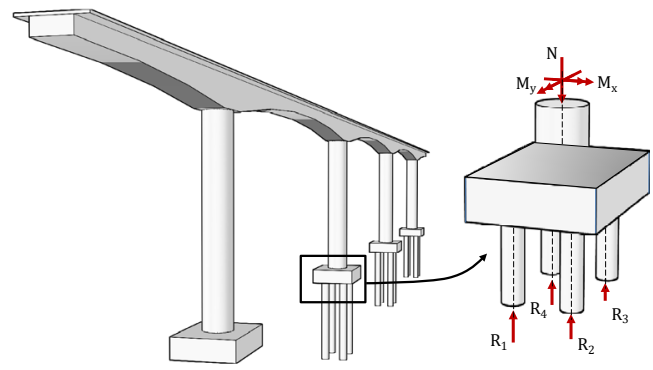

(b)

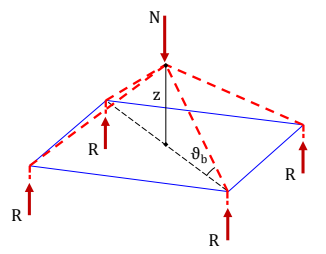

Con formato: Resaltar

Comentado [L1]: Valorar si esto vale... Sensitivity of formulations against the increase of strength due to?????

Con formato: Color de fuente: Rojo

Con formato: Color de fuente: Rojo

Con formato: Color de fuente: Rojo

Con formato: Color de fuente: Rojo 
84 by EC-2,ACI 318-14 and Model Code 2010 [27] for pile cap design, including the case of eccentric loads on 85 the column.

\section{3. Code provisions for pile caps}

\section{$87 \quad$ 3.1. Strut and tie models}

Pile caps can be considered as discontinuity (D) regions due to the proximity of the applied load to the 89 reactions of the piles. In the definition of the STM (e.g. Fig.1Fig. 1b), the location of the upper multicompressed node $(z)$ is a determining factor. Its position affects the strut inclination and hence the tie forces.

91 Although the maximum stresses of concrete in struts and nodal regions hasneed to be verified, the codes do 92 not give specific recommendations for the three-dimensional case. Section13.4.2.4 of ACI 318-14 indicates

93 that the effective compressive strength of the struts $\left(f_{c e}\right)$ should be restricted to $0.85 \beta_{s} f_{c,}$, with $\beta_{s}=0.6 \lambda$ for

94 bottle-shaped struts and $\lambda=1$ in the case of normal weight concrete. A review of the existing proposals for 95 extending STMs to foundations under eccentric loads is carried out as follows.

Souza et al. [16] locate the multi-compressed node on the upper surface of the pile cap ( $z=1.0 d)$. These authors propose avoiding the splitting of the struts by limiting the maximum stress in the concrete of the column section to $1.0 f_{t}$ This proposal [16] only applies to smalleccentricity values as it does not consider the possible transmiscion of tensile forces from the column.

Con formato: Color de fuente: Rojo

Con formato: Color de fuente: Rojo

Con formato: Color de fuente: Rojo Con formato: Color de fuente: Rojo Con formato: Color de fuente: Rojo

Con formato: Color de fuente: Rojo, Inglés (Estados Unidos) Con formato: Sangría: Primera línea: $0 \mathrm{~cm}$ 
The fib Bulletin 61 [24] includes two examples of STM for axially loaded footings subjected to uniaxial and biaxial bending. The definition of the height of the upper node is fixed at around $z=0.90 \mathrm{~d}$ from the reinforcement plane. Verifying the stresses in this nodal region is simplified in the uniaxial bending case by projecting the forces of the struts on the symmetry plane and carrying out the usul check of the wdimensional CCC node. Howerer, this analogy is not valid for biaxial bending.

The ACHE M6 monograph [25] gives an example of the STM for a pile cap with six piles and combined axial and bending loads. As in Souza et al. [16], it locates the upper node at $z=1.0 d$, and points out that the multi-compressive node does not need any special check. The lower nodal regions are verified assuming that the struts have an elliptic section and the stress is limited to $0.70 f_{e}$

ACI Special Publication 273 [26] provides an example of a four-pile cap subjected to a more eccentric load than the previous cases. The upper node is located at around $z=0.90 \mathrm{~d}$. Verification of the nodal regions consists of restricting the compressive stresses in the bearing areas to $0.85 f_{t}$

\section{All these proposals involve conservative hypotheses on the location of the upper node ( $z$ ) and offer}

simplified criteria to verify the stresses in the concrete. According to Miguel-Tortola et al. [15], for three-pile caps under centered load, the obtained STM provide safe designs since they are based on the Lower Bound Theorem of Plasticity, but they become excessively conservative and do not detect the increased resistance increase when slenderness decreases or when vertical secondary reinforcement is added.

\subsection{Sectional approach: flexure, shear and punching}

EC-2 and ACI 318-14 allow for the design of pile caps by sectional methods, including flexure, shear and punching capacities.

\subsubsection{Flexure}

Both codes allow verification of the pile cap flexural capacity in a vertical plane located on the edge of the column and extended to the whole width of the pile cap (section (1) inat Fig.2Fig. Za). Furthermore, CSRI [23] recommends a control section for bending (section (2) atin Fig.2Fig. 2a) at $c / 4$ from the column centre line, while EC-2 limits the design moment to a maximum value of 0.65 times the moment at the support axis 
(a) PLAN VIEW

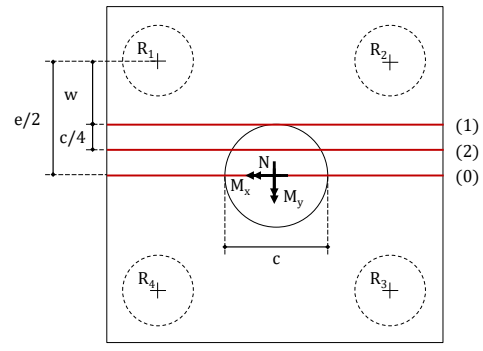

(b) ELEVATION $\mathrm{B}$

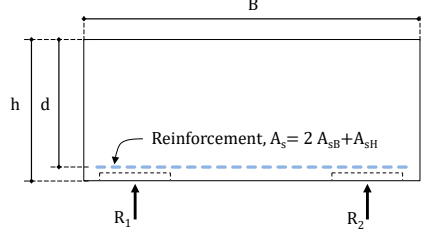

SIDE SECTION

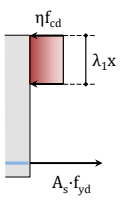

137

138

139

140

Fig.2 Flexural strength of pile caps: a) Location of control sections for bending; b) Rectangular stress distribution along the pile cap section

Table 1 Parameters defining the rectangular stress distribution of concrete

\begin{tabular}{ccc}
\hline$\eta$ & $\lambda_{1}$ \\
\hline \multicolumn{3}{c}{ EC-2, MC-2010 } \\
\hline 1 & 0.8 & for $f_{c k} \leq 50 \mathrm{MPa}$ \\
$1-\left(f_{c k}-50\right) / 200$ & $0.8-\left(f_{c k}-50\right) / 400$ & for $50<f_{c k} \leq 50 \mathrm{MPa}$ \\
\hline \multicolumn{3}{c}{ ACI $318-14$} \\
\hline 0.85 & 0.85 & for $17<f_{c} \leq 28 \mathrm{MPa}$ \\
& $0.85-0.05 \cdot\left(f_{c}-28\right) / 7$ & for $28<f_{c} \leq 55 \mathrm{MPa}$ \\
& 0.65 & for $f_{c} \geq 55 \mathrm{MPa}$ \\
\hline
\end{tabular}

$\lambda_{1}$ : factor defining the height of the compression zone;

$\eta$ : factor defining the effective strength; $f_{c k}$ : characteristic value of

compressive strength of concrete; $f_{c}$ cylinder compressive strength of concrete 
(a)

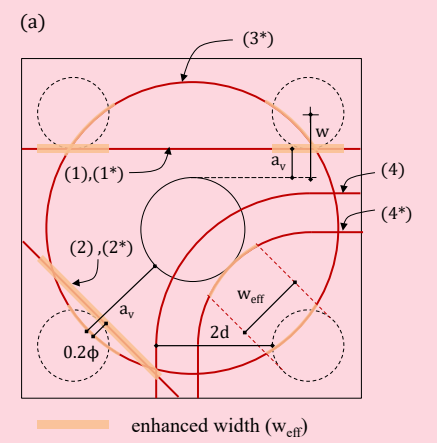

(b)

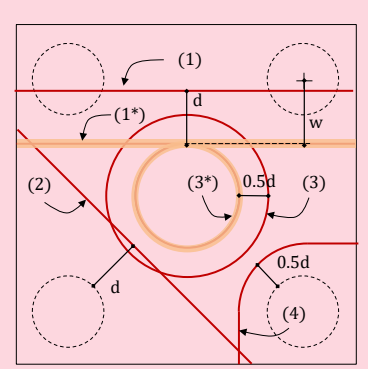

(c)

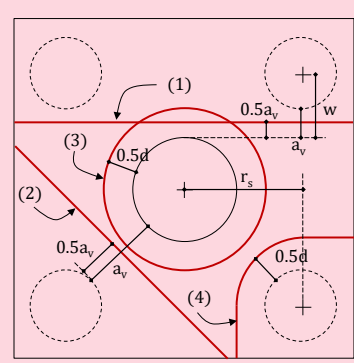

Fig.3 Control sections associated with different punching shear failure modes according to: (a) EC-2; (b) ACI 318-1444; (c) MC-2010. Note: when section (1) goes through the piles, it is considered tangent to them

Table 2 Summary of the main parameters in the shear and punching formulations of EC-2

Control

section Shear force factors

Members without shear reinforcement

Members with shear reinforcement
Con formato: Color de fuente: Rojo

Con formato: Color de fuente: Rojo

Con formato: Color de fuente: Rojo

Con formato: Color de fuente: Rojo

Con formato: Fuente: (Predeterminada) Cambria Math

Comentado [PMS2]: Falta la cotad 2d en la sección de control 3* del EC2

Con formato: Color de fuente: Rojo 


\begin{tabular}{|c|c|c|c|c|c|c|}
\hline \multirow{2}{*}{$\begin{array}{l}\text { 3) } \\
b / u_{1}\end{array}$} & \multirow[b]{2}{*}{$1 / x$} & \multirow[b]{2}{*}{$\beta$} & \multirow[b]{2}{*}{$v_{R d, c}$} & \multirow[b]{2}{*}{$\chi$} & \multirow[b]{2}{*}{$W_{e f f}$} & \\
\hline & & & & & & \\
\hline (1), (2) & $\frac{a_{v}}{2 d}$ & $\mathrm{x}$ & $\frac{0.18}{\gamma_{c}} k\left(100 \rho_{l} f_{c k}\right)^{\frac{1}{3}}$ & $\mathrm{x}$ & $\mathrm{x}$ & $\begin{array}{l}\text { minimum of: } \\
\left\{\begin{array}{c}V_{R d, c}+A_{s w} f_{y w d} \cot \theta_{b} \\
0.6 f_{c k} b z /\left(\cot \theta_{b}+\tan \theta_{b}\right)\end{array}\right. \\
A_{s w} \text { within } 0.75 a_{V} \text { and } 1 \leq \cot \vartheta_{b} \leq 2.5\end{array}$ \\
\hline$\left(1^{*}\right),\left(2^{*}\right)$ & $\mathrm{x}$ & $\mathrm{x}$ & $\frac{0.18}{\gamma_{c}} k\left(100 \rho_{l} f_{c k}\right)^{\frac{1}{3}}$ & $\frac{2 d}{a_{v}}$ & $\mathrm{n} \cdot \phi$ & $\begin{array}{l}V_{R d, c *}+A_{s w} f_{y w d} \\
A_{s w} \text { within } 0.75 a_{V}\end{array}$ \\
\hline (4) & $\mathrm{x}$ & $1+\gamma_{v} e_{u} \frac{u_{1}}{W_{1}}$ & $\frac{0.18}{\gamma_{c}} k\left(100 \rho_{l} f_{c k}\right)^{\frac{1}{3}}$ & $\mathrm{x}$ & $\mathrm{x}$ & $\begin{array}{l}0.75 V_{R d, c}+A_{s w} f_{y w d} \\
A_{s w} \text { within } 0.75 \text { of } 2 d\end{array}$ \\
\hline$\left(3^{*}\right),\left(4^{*}\right)$ & $\mathrm{x}$ & $1+\gamma_{v} e_{u} \frac{u_{1}}{W_{1}}$ & $\frac{0.18}{\gamma_{c}} k\left(100 \rho_{l} f_{c k}\right)^{\frac{1}{3}}$ & $\frac{2 d}{a_{v}}$ & $\mathrm{n} \cdot \phi$ & $\begin{array}{l}0.75 V_{R d, c}+A_{s w} f_{y w d} \\
A_{s w} \text { within } 0.75 \text { of } 2 d\end{array}$ \\
\hline
\end{tabular}

(1),(2): shear planes of failure

(3): control section of punching around the column

(4): control section of punching around the pile

$b$ : effective breadth for shear; $u_{1}$ : basic control perimeter; $1 / \chi$. factor for load-support proximity; $\beta$ : coefficient of eccentricity; $v_{R d, c}$ stress corresponding to punching strength provided by concrete; $\chi$. enhancement factor of concrete strength; Weff: effective width for the shear enhancement factor; $a_{v}$ c clear span; d: effective depth; $k$ : factor that takes into account the size effect, equal to $1+\sqrt{(\mathrm{d} / 200)} \leq 2.0 ; \rho_{\text {f }}$ steel reinforcement ratio; $f_{c k}$ : characteristic value of compressive strength of concrete; $\gamma_{c}$ : partial safety factor for concrete material properties; $V_{R d, c}$ p punching shear resistance of concrete; $V_{R d, c}$ : enhanced punchin shear resistance of concrete; $A_{s w:}$ p punching shear reinforcement area; $f_{y w d}$ : design yield strength of the shear reinforcement; $\vartheta_{b:}$ inclination of the compressive stress field (struts); $\gamma_{v}$ factor used to determine the fraction of bending moment transferred by eccentricity of shear at slab-column connections; $e_{u}$ : eccentricity of the resultant shear forces; $W_{1}$ : property of assumed critical section analogous to plastic section modulus

When verifying shear, EC-2 considers the positive effect of the proximity of the load to the support by

means of a load reduction factor $(1 / \chi)$, refer to Eq. (2) (2). This point is discussed in the Designers' Guide to

EN 1992-2 [21], since the experimental results with beams show increased shear resistance in sections

located close to the support. Based on BS 8110 [28] and BS 5400 [29], the guide proposes the use of an enhancement factor of concrete strength $(\chi)$ on the areas in which the reinforcement is fully anchored by passing across the head of a pile ( $\left.w_{e f f}\right)$. This proposal is summarised by Eq.(3):

$$
\begin{gathered}
\left(\frac{1}{\chi}\right) V_{E d} \leq v_{R d, c} b d=V_{R d, c} \\
V_{E d} \leq v_{R d, c}\left[b+(\chi-1) w_{e f f}\right] d=V_{R d, c}
\end{gathered}
$$

Should there be shear reinforcement, the shear strength is governed by yielding of stirrups or web crushing, with a variable inclination of the compressive stress field $\left(\theta_{b}\right)$. When the enhancement factor of concrete strength $(\chi)$ is applied, the Designers' Guide to EN 1992-2 [21] proposes a simpler approach: adding the stirrups' contribution $\left(\mathrm{V}_{\mathrm{Rd}, s}\right)$ to the enhanced concrete shear strength provided by its effective 
width $\left(V_{R d, c^{*}}=v_{R d, c} \cdot \mathcal{X} \cdot W_{\text {eff }} d\right)$. Table 2Table 2 shows the formulations of both approaches for the shear planes described in Fig.3Fig. 3a.

As regards the punching verification, EC-2 allows the use of the enhancement factor of concrete strength $(\chi)$ to verify internal control perimeters in column bases, but this is not applicable when loads are concentrated close to the column (pile reactions), according to clause 6.4.3 (7) of EC-2. Here again the Designers' Guide to EN 1992-2 [21] questions this point; not considering any improved resistance effect can be very conservative, while considering it effective in the entire punching perimeter would be unsafe. In this regard, the proposal by Clarke [2] was to enhance concrete strength over an effective width as indicated in section $\left(3^{*}\right)$ and $\left(4^{*}\right)$ of Fig. 3 Fig. 3a. Table 2Table 2 gives details of these considerations for these control sections.

With an eccentric point load, part of the bending moment $\left(\gamma_{v} M\right)$ is resisted by the variation of the shear stresses in the punching control section [30]. To allow for this effect, the EC-2 proposes a plastic distribution of the stresses at the control perimeter $\left(u_{1}\right)$. The maximum punching shear stress is the result of multiplying the average stress $\left(\nu_{E d}\right)$ by the eccentricity factor $\beta$ indicated in Table 2Table 2. Eq.(4)(4) gives the complete punching verification proposal for eccentric loads:

$$
\beta V_{E d} \leq v_{R d, c}\left[u_{1}+(\chi-1) w_{e f f}\right] d=V_{R d, c}
$$

For those members reinforced with stirrups, punching strength is the sum of $75 \%$ of concrete resistance $\left(V_{R d, c}\right)$ and the contribution of the shear reinforcement $\left(V_{R d, s}\right)$.

\subsubsection{ACI 318-14}

The punching and shear control sections defined in ACI 318-14 are located at 0.5 $d$ and $d$, respectively, from the edge of the pointloaded area or supportpile section (sections (1) a (4) of Fig.3Fig. 3b). The recent CRSI Design Guide for Pile Caps [23]adds the two control sections $\left(1^{*}\right)$ and $\left(3^{*}\right)$ indicated in Fig.3Fig. $3 \mathrm{~b}$, wherewhich considers enhanced shear and punching strength.

Table 3 Summary of the main parameters in the shear and punching formulations of ACI 318-14

\begin{tabular}{|c|c|c|c|}
\hline $\begin{array}{l}\text { Control } \\
\text { section }\end{array}$ & Shear force factors & Members without shear reinforcement & $\begin{array}{l}\text { Members with shear } \\
\text { reinforcement }\end{array}$ \\
\hline
\end{tabular}




\begin{tabular}{|c|c|c|c|c|c|c|}
\hline \multirow{2}{*}{$\begin{array}{c}\frac{(\text { Fig.3Fig. }}{3)} \\
b / u_{1}\end{array}$} & & & & & & \\
\hline & $1 / x$ & $\beta$ & $v_{R d, c}$ & $x$ & $W_{e f f}$ & \\
\hline (1) & $\mathrm{x}$ & $\mathrm{x}$ & $\begin{array}{l}\text { minimum of: } \\
\left\{\begin{array}{c}0.16 \lambda \sqrt{f_{c}}+17 \rho_{l} \frac{V_{1}}{M_{1}} d \\
0.16 \lambda \sqrt{f_{c}}+17 \rho_{l} \\
0.29 \lambda \sqrt{f_{c}}\end{array}\right.\end{array}$ & $\mathrm{x}$ & $\mathrm{x}$ & $\begin{array}{l}V_{R d, c}+A_{s w} f_{y w d}, \\
\text { A }_{s w} \text { within d }\end{array}$ \\
\hline $\begin{array}{c}\left(1^{*}\right) \\
\mathrm{w} / \mathrm{d}<1\end{array}$ & $\mathrm{x}$ & $\mathrm{x}$ & $0.16 \lambda \sqrt{f_{c}}+17 \rho_{l} \frac{V_{1 *}}{M_{1 *}} d$ & $\frac{d}{w}\left[3.5-2.5\left(\frac{M_{1 *}}{V_{1 *} d}\right)\right]$ & $\mathrm{b}$ & $\begin{array}{l}V_{R d, c}+A_{s w} f_{y w d} \\
\mathrm{~A}_{s w} \text { within d }\end{array}$ \\
\hline (2) & $\mathrm{x}$ & $\mathrm{x}$ & $0.17 \lambda \sqrt{f_{c}}$ & $\mathrm{x}$ & $\mathrm{x}$ & $\begin{array}{l}V_{R d, c}+A_{s w} f_{y w d} \\
\text { Asw within d }\end{array}$ \\
\hline (3), (4) & $\mathrm{x}$ & $1+\frac{\gamma_{v} e_{u} c_{A B} u_{1} d}{J_{c}}$ & $\begin{array}{l}\text { minimum of: } \\
\left\{\begin{array}{c}0.33 \lambda \sqrt{f_{c}} \\
0.17\left(1+\frac{2}{c_{1} / c_{2}}\right) \lambda \sqrt{f_{c}} \\
0.083\left(2+\frac{\alpha_{s} d}{u_{1}}\right) \lambda \sqrt{f_{c}}\end{array}\right.\end{array}$ & $\mathrm{x}$ & $\mathrm{x}$ & $\begin{array}{l}\text { minimum of: } \\
\left\{\begin{array}{c}0.17 \lambda \sqrt{f_{c}} u_{1} d+A_{s w} f_{y w d} \\
\phi_{f} 0.5 \sqrt{f_{c}} u_{1} d\end{array}\right. \\
\mathrm{A}_{\mathrm{sw}} \text { within } \mathrm{d}\end{array}$ \\
\hline $\begin{array}{c}\left(3^{*}\right) \\
\mathrm{w} / \mathrm{d}<0.5\end{array}$ & $\mathrm{x}$ & $1+\frac{\gamma_{v} e_{u} c_{A B} u_{0} d}{J_{c}}$ & $0.17 \lambda \sqrt{f_{c}}$ & $\frac{d}{w}\left(1+\frac{d}{c}\right)$ & $\mathrm{u}_{0}$ & Not considered \\
\hline
\end{tabular}

(1),(2): shear planes of failure

(3): control section of punching around the column

(4): control section of punching around the pile

$b$ : effective breadth for shear; $u_{1}$ : basic control perimeter; $1 / x$ : factor for load-support proximity; $\beta$ : coefficient of eccentricity; $\nu_{R d, i}$ stress corresponding to punching strength provided by concrete; $\chi$. enhancement factor of concrete strength;

$W_{\text {eff }}$ effective width for the shear enhancement factor; d: effective depth; $\rho_{l}$ : steel reinforcement ratio; $\lambda$ : modification factor to account for the properties of lightweight concrete; $f_{c}$ cylinder compressive strength of concrete; $V_{1}, V_{1}$ * shear force at control section (1) or (1*); $M_{1}, M_{1}$ * bending moment at control section (1) or (1*); $w$ : shear span; $V_{R d, c}$ : punching shear resistance of concrete; $A_{s w}$ : punching shear reinforcement area; $f_{y w d}$ design yield strength of the shear reinforcement; $\gamma_{v:}$ factor used to determine the fraction of bending moment transferred by eccentricity of shear at slab-column connections; $e_{u}$ : eccentricity of the resultant shear forces; $c_{A B}$ : length of the side of the equivalent rectangular control section, parallel to the bending axis;

$u o$ : column or pile perimeter; $J_{c}$ property of assumed critical section analogous to polar moment of inertia; $c_{i}$ : long side of the column; $c_{2}$ : short side of the column; $\alpha_{s}$ : 40 for interior columns, 30 for edge columns, 20 for corner columns; $c$ c column diameter/side; $\phi_{\text {f }}$ strength reduction factor, 0.75 for shear

Table 3 Table 3 contains a summary of the concrete shear strength $\left(\nu_{R d, c}\right)$ and the enhancement factor

$(\chi)$ to be used in Eq. (5) (5) for shear verification. If shear reinforcement is provided, its contribution $\left(V_{R d, s}\right)$ is added to the strength provided by the concrete section $\left(V_{R d, c}\right)$.

$$
V_{E d} \leq \chi v_{R d, c} b_{w} d=V_{R d, c}
$$

Shear verification can consider the transfer of bending moment between the column and the slab $\left(\gamma_{v} M\right)$, accepting a linear distribution of shear stresses around the control perimeter $\left(u_{1}\right)$. A $\beta$ factor is defined (refer to Table 3Table 3) to find the maximum shear stress. Eq.(6)(6)gives a brief shear formulation for pile caps whose slenderness is $w / d>0.5$. If shear reinforcement is considered, its contribution $\left(V_{R d, s}\right)$ can be added to that of the concrete limited to $0.17 \lambda \sqrt{f_{c} \text {. }}$ 


$$
\beta V_{E d} \leq v_{R d, c} u_{1} d=V_{R d, c}
$$

For deeper pile caps (w/d $\leq 0.5)$, the CSRI's Special Investigation [31] proposes evaluating the enhanced

$$
V_{E d} \leq \chi v_{R d, c} u_{0} d=V_{R d, c}
$$

\subsubsection{Model Code 2010}

The punching shear formulation is developed from the Critical Shear Crack Theory (CSCT) proposed by

Muttoni \& Schwartz [32], according to which the shear strength of beams or slabs is a function of the width

rotation $(\psi)$ and maximum aggregate size $\left(d_{g}\right)$ in slabs.

To determine $\varepsilon_{x}$ and $\psi$, four levels of approximation are established in MC-2010, ordered from lower to

higher complexity and accuracy. Table 4Table 4 gives the formulation of the Level I of Approximation (LoAI), as this is considered to be the most similar to those proposed in EC-2 and ACI 318-14.

The definition of the control sections is similar to that proposed in ACI 318-14: $0.5 d$ from the edge of the pointloaded area or punching support, and the smallest between $d$ and $0.5 a_{v}$ for shear with loads close to supports. The four control sections are those indicated in Fig.3Fig. 3c: shear parallel to column situated at $d$ (1), corner shear situated at $d(2)$, punching around the column (3) and punching around the pile at $0.5 d$ (4).

\begin{tabular}{|c|c|c|c|c|c|c|}
\hline \multirow{2}{*}{$\begin{array}{c}\text { Control } \\
\text { section } \\
\text { (Fig.3Fig. } \\
3 \text { ) } \\
b / u_{1}\end{array}$} & \multicolumn{2}{|c|}{ Shear force factors } & \multicolumn{3}{|c|}{ Members without shear reinforcement } & \multirow[t]{2}{*}{ Members with shear reinforcement } \\
\hline & $1 / x$ & $\beta$ & $\nu_{R d, c}$ & $\chi$ & Weff & \\
\hline$(1),(2)$ & $\frac{a_{v}}{2 d} \geq 0.5$ & $\mathrm{x}$ & $\begin{array}{c}k_{v} \frac{\sqrt{f_{c k}}}{\gamma_{c}}, \text { with } \\
k_{v}=\frac{180}{1000+1.25 z}\end{array}$ & $\mathrm{x}$ & $\mathrm{x}$ & $\begin{array}{l}\text { minimum of: } \\
\left\{\begin{array}{l}A_{s w} f_{y w d} \cot \theta_{b} \\
0.55\left(\frac{30}{f_{c k}}\right)^{1 / 3} \frac{f_{c k}}{\gamma_{c}} b z \sin \theta_{b} \cos \theta_{b}\end{array}\right.\end{array}$ \\
\hline
\end{tabular}

Table 4 Summary of the main parameters in the shear and punching formulations of MC-2010 
(3), (4) $\quad \mathrm{x} \quad \frac{1}{1+e_{u} / b_{u}}$

$$
\begin{gathered}
k_{\psi} \frac{\sqrt{f_{c k}}}{\gamma_{c}}, \text { with } \\
k_{\psi}=\frac{1}{1.5+0.9 k_{d g} \psi d} \leq 0.6 \\
\psi=1.5 \frac{r_{s}}{d} \frac{f_{y d}}{E_{s}} ; \quad k_{d g}=\frac{32}{16+d_{g}}
\end{gathered}
$$

General $\quad \mathrm{x} \quad V_{R d, c}+A_{s w} k_{e} \sigma_{s w d}$

procedure:

$\mathrm{Eq}_{2}(9)(9)$

$\sigma_{s w d}=\frac{E_{s} \psi}{6}\left(1+\frac{f_{b d}}{f_{y w d}} \frac{d}{\phi_{w}}\right) \leq f_{y w d}$

Asw within $d_{v}$ and $0.35 d_{v}$

$b$ : effective breadth for shear; $u_{1}$ : basic control perimeter; $1 / \chi$. factor for load-support proximity; $\beta$ : coefficient of eccentricity; $\nu_{R d, i}$ stress corresponding to punching strength provided by concrete; $\chi$. enhancement factor of concrete strength;

$w_{\text {eff }}$ effective width for the shear enhancement factor; $a_{v}$ clear span; d: effective depth; $z$ l level arm $0.9 d_{v ;} ; f_{c k}$ characteristic value of compressive strength of concrete; $\gamma_{c}$ : partial safety factor for concrete material properties; $V_{R d, c} \dot{a}$ punching shear resistance of concrete; $A_{s w:}$ punching shear reinforcement area; $f_{y w d}$ design yield strength of the shear reinforcement; $\vartheta_{b}$ : inclination of the compressive stress field (struts); $r_{s}$ : position where the radial bending moment is zero with respect to the support axis; $f_{y d}$ design yield strength of reinforcing steel in tension; $E_{\text {s: }}$ modulus of elasticity of flexural and shear reinforcement; $d_{g:}$ maximum size of aggregate; $d_{v:}$ effective depth considering support penetration;

Similarly to EC-2, for shear verification (refer to Eq.(2)(2)), whetherif the load is close to the support $(w<2 d)$, punching strength can be reduced by the factor $1 / \chi$ given in Table 4 Table 4 . Also, shear strength of beams with stirrups is governed by yielding of this shear reinforcement or web crushing, with a variable inclination of the compressive stress field (refer to Table 4Table 4).

In the punching verification (refer to Eq.(8)(8)), a shear-resisting control perimeter is defined $\left(u_{2}\right)$ that allows for the possible non-uniform distribution of the shear forces along the basic control perimeter $\left(u_{1}\right)$.

This can be due either to the presence of loads close to the support or to the concentration of the shear forces due to moment transfer between column and slab. The former case is dealt with in the general method described in Eq.(9)(9), which requires a shear field analysis to determine the maximum shear per unit of length perpendicular to the control perimeter ( $\left.v_{p e r p, d, \max }\right)$ [33]. In the latter case MC-2010 applies its eccentricity coefficient $\beta$ to the basic control perimeter (Eq. (10) $(10))$.

$$
\begin{gathered}
V_{E d} \leq v_{R d, c} u_{2} d_{v}=V_{R d, c} \\
u_{2}=\frac{V_{E d}}{v_{\text {perp }, d, \max }} \\
u_{2}=\beta u_{1}
\end{gathered}
$$

The contribution of the punching reinforcement to resistance depends on the rotation achieved in the

Con formato: Español (España)

Con formato: Sin Resaltar

Con formato: Sin Resaltar 
The main features of the punching formulation in the codes may be summarized as follows: horizontal secondary reinforcement is not taken into account in ACI-318-14 and CM2010 (LoA I), only is considered in EC2; the three codes add the contribution of shear reinforcement to the component resisted by concrete, but they differ in the reinforcement area considered; the eccentricity of the applied load is taken to account by means of a factor -the load is amplified in ACI and EC2 and the shear-resisting perimeter is reduced in CM2010-; and the influence of loads close to the control section is taken to account by means of an enhanced strength over an effective width (EC2 and ACI) or by means of modifying the control perimeter length (CM2010).

The variety of locations of the control sections and the different way of considering the effects of concentrated loads of piles and the eccentricity of the applied load lead to codes differ considerably in both the predicted strength and the mode of failure for a same cap.

\section{Experimental research}

\subsection{Specimen design}

21 four-pile caps were tested grouped in three different series. Series N: centered load $\left(e_{x}=e_{y}=0\right)$; series NMM: biaxial bending $\left(e_{x}=e_{y}=0.11 \mathrm{~m}\right)$; series NM, uniaxial bending $\left(e_{x}=0.15 \mathrm{~m}, e_{y}=0\right)$. With the aim of assessing the influence of the shear span-depth ratio and secondary reinforcement on pile cap strength, each series was defined by combinations of three different depths and reinforcement layouts (Table 5Table 5).

The following dimensions were identical in all specimens (Fig.4Fig. 4a): pile spacing ( $e=0.80 \mathrm{~m})$, shear span $(w=0.23 \mathrm{~m})$, pile diameter $(\phi=0.25 \mathrm{~m})$, column diameter $(c=0.35 \mathrm{~m})$ and slab plane size $(1.15 \times 1.15 \mathrm{~m})$. Three different pile cap depths (h) were prepared: Type A - 0.25 m; Type B - 0.35 m; Type C - $0.45 \mathrm{~m}$. All of them fulfill the deep pile cap requirement (w/d $\leq 2)$, see Table 7Fable 7. Fig.4Fig. $4 b-d$ shows the three reinforcement layouts considered: Type 1 - bunched reinforcement $\left(A_{s B}\right)$; Type 2 - distributed reinforcement 

Fig.5Fig. $5 \mathrm{a}$ with a design load of $500 \mathrm{kN}$. This reinforcement was maintained in the eccentric series in order

261 to compare their strengths. It should be noted that type-1 reinforcement layout could not conform with code 262 recommendations because it would fail the crack width verification. This type of reinforcement layout is just 263 considered as a reference, only for research purpose. 
Table 5 Key features of pile cap specimens

\begin{tabular}{|c|c|c|c|c|c|c|}
\hline Specimen & $\begin{array}{l}h / d \\
(\mathrm{~m})\end{array}$ & $\begin{array}{c}e_{X} \\
(\mathrm{~m})\end{array}$ & $\begin{array}{c}e_{y} \\
(\mathrm{~m})\end{array}$ & $\begin{array}{c}A_{S B} \\
\left(\mathrm{~cm}^{2}\right)\end{array}$ & $\begin{array}{c}A_{s H} \\
\left(\mathrm{~cm}^{2}\right)\end{array}$ & $\begin{array}{c}A_{s V} \\
\left(\mathrm{~cm}^{2}\right)\end{array}$ \\
\hline $4 \mathrm{P}-\mathrm{N}-\mathrm{A} 1$ & $0.25 / 0.19$ & - & - & $4 \times(2 \varphi 16+1 \varphi 12)$ & - & - \\
\hline $4 \mathrm{P}-\mathrm{N}-\mathrm{A} 2$ & $0.25 / 0.19$ & - & - & $4 x(2 \varphi 16+1 \varphi 12)$ & $4 \times 5 \varphi 10$ & - \\
\hline $4 \mathrm{P}-\mathrm{N}-\mathrm{A} 3$ & $0.25 / 0.19$ & - & - & $4 x(2 \varphi 16+1 \varphi 12)$ & $4 \times 5 \varphi 10$ & $4 \times 5 s \varphi 8$ \\
\hline 4P-N-B1 & $0.35 / 0.30$ & - & - & $4 \times 3 \varphi 12$ & - & - \\
\hline 4P-N-B2 & $0.35 / 0.30$ & - & - & $4 \times 3 \varphi 12$ & $4 \times 5 \varphi 8$ & - \\
\hline 4P-N-B3 & $0.35 / 0.30$ & - & - & $4 \times 3 \varphi 12$ & $4 \times 5 \varphi 8$ & $4 \times 5 s \varphi 8$ \\
\hline $4 \mathrm{P}-\mathrm{N}-\mathrm{C} 1$ & $0.45 / 0.40$ & - & - & $4 x(2 \varphi 10+1 \varphi 12)$ & - & - \\
\hline $4 \mathrm{P}-\mathrm{N}-\mathrm{C} 2$ & $0.45 / 0.40$ & - & - & $4 x(2 \varphi 10+1 \varphi 12)$ & $4 \times 5 \varphi 8$ & - \\
\hline $4 \mathrm{P}-\mathrm{N}-\mathrm{C} 3$ & $0.45 / 0.40$ & - & - & $4 x(2 \varphi 10+1 \varphi 12)$ & $4 \times 5 \varphi 8$ & $4 \times 5 s \varphi 8$ \\
\hline 4P-NMM-A2 & $0.25 / 0.19$ & 0.11 & 0.11 & $4 x(2 \varphi 16+1 \varphi 12)$ & $4 \times 5 \varphi 10$ & - \\
\hline 4P-NMM-A3 & $0.25 / 0.19$ & 0.11 & 0.11 & $4 x(2 \varphi 16+1 \varphi 12)$ & $4 \times 5 \varphi 10$ & $4 \times 5 s \varphi 8$ \\
\hline 4P-NMM-B2 & $0.35 / 0.30$ & 0.11 & 0.11 & $4 \times 3 \varphi 12$ & $4 \times 5 \varphi 8$ & - \\
\hline 4P-NMM-B3 & $0.35 / 0.30$ & 0.11 & 0.11 & $4 \times 3 \varphi 12$ & $4 \times 5 \varphi 8$ & $4 \times 5 s \varphi 8$ \\
\hline 4P-NMM-C2 & $0.45 / 0.40$ & 0.11 & 0.11 & $4 x(2 \varphi 10+1 \varphi 12)$ & $4 \times 5 \varphi 8$ & - \\
\hline 4P-NMM-C3 & $0.45 / 0.40$ & 0.11 & 0.11 & $4 x(2 \varphi 10+1 \varphi 12)$ & $4 \times 5 \varphi 8$ & $4 \times 5 s \varphi 8$ \\
\hline 4P-NM-A2 & $0.25 / 0.19$ & 0.15 & - & $4 x(2 \varphi 16+1 \varphi 12)$ & $4 \times 5 \varphi 10$ & - \\
\hline 4P-NM-A3 & $0.25 / 0.19$ & 0.15 & - & $4 x(2 \varphi 16+1 \varphi 12)$ & $4 \times 5 \varphi 10$ & $4 \times 5 s \varphi 8$ \\
\hline 4P-NM-B2 & $0.35 / 0.30$ & 0.15 & - & $4 \times 3 \varphi 12$ & $4 \times 5 \varphi 8$ & - \\
\hline 4P-NM-B3 & $0.35 / 0.30$ & 0.15 & - & $4 \times 3 \varphi 12$ & $4 \times 5 \varphi 8$ & $4 \times 5 s \varphi 8$ \\
\hline 4P-NM-C2 & $0.45 / 0.40$ & 0.15 & - & $4 x(2 \varphi 10+1 \varphi 12)$ & $4 \times 5 \varphi 8$ & - \\
\hline 4P-NM-C3 & $0.45 / 0.40$ & 0.15 & - & $4 \mathrm{x}(2 \varphi 10+1 \varphi 12)$ & $4 \times 5 \varphi 8$ & $4 \times 5 s \varphi 8$ \\
\hline
\end{tabular}

$h$ : pile cap depth; $d$ : effective depth; $e_{x:}$ eccentricity from x-axis; $e_{y}$ eccentricity

from y-axis; $A_{S B}$ main bunched reinforcement area; $A_{s H}$ : horizontal secondary

reinforcement area; $A_{s} v$. vertical secondary reinforcement area (in stirrups);

$\varphi$ : diameter of steel reinforcement; 
(a)
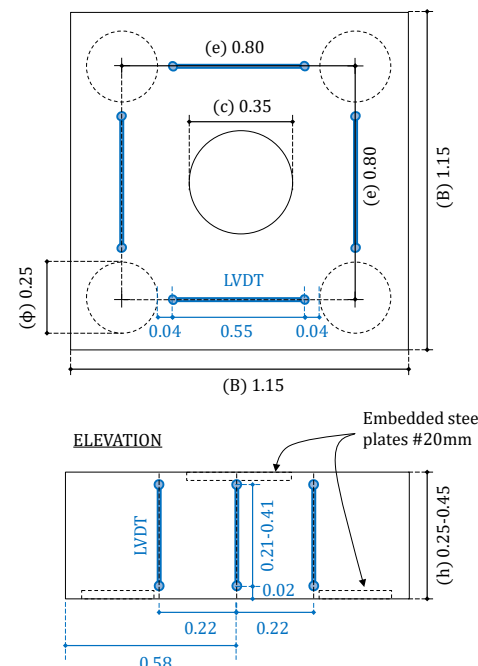

(b)

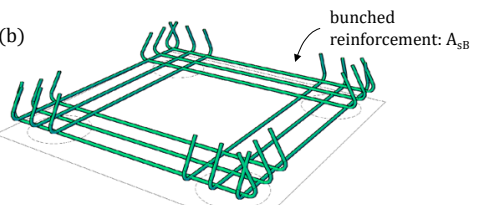
(c) horizontal sec.

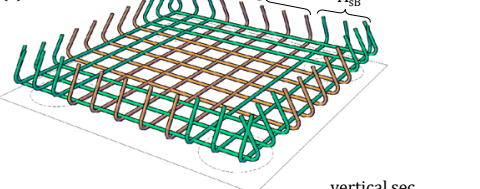

vertical sec.
reinforcement

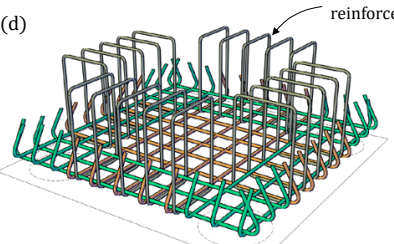

Fig.4 Specimen geometry and reinforcement layout: (a) Main dimensions and LVDT location; (b) Type 1: $A_{s B} ;$ (c) Type 2: $A_{s B}+A_{s H}$; (d) Type 3: $A_{s B}+A_{s H}+A_{s V}$

(a)

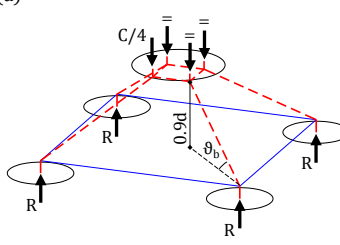

(b)

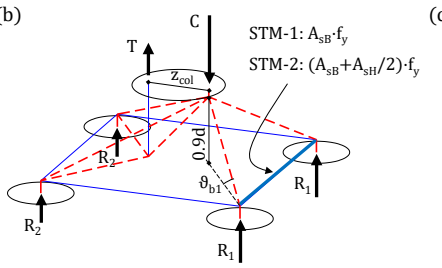

(c)

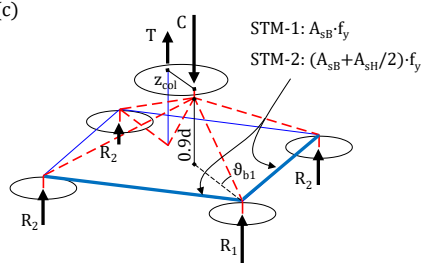

Fig.5 STM based on the SP-273 of ACI: a) centered load; b) uniaxial bending; c) biaxial bending

\subsection{Material properties}

The first column in Table 7Table 7 includes the average compressive and tensile strengths and ages of the concrete cylinders tested under the same temperature and humidity conditions as the pile caps.

Compressive strength $\left(f_{c}\right)$ ranged from 25.3MPa to 39.2MPa, and tensile strength $\left(f_{c t}\right)$ from $2.2 \mathrm{MPa}$ to

3.8MPa. The maximum aggregate size $\left(d_{g}\right)$ was $12 \mathrm{~mm}$.

Two samples of reinforcement of $60 \mathrm{~cm}$ in length per diameter were tested under tension (ISO 15630$1: 2010[34])$ to determine an average value for yield $\left(f_{y}\right)$ and ultimate strength $\left(f_{u}\right)$. Table 6 Table 6 offers the average mechanical properties of reinforcement.

Con formato: Fuente: 11 pto

Con formato: Fuente: 11 pto 
Table 6 Mechanical properties of reinforcement

\begin{tabular}{lccc}
\hline Series & $\begin{array}{c}\varphi \\
(\mathrm{mm})\end{array}$ & $\begin{array}{c}f_{y} \\
(\mathrm{MPa})\end{array}$ & $\begin{array}{c}f_{u} \\
(\mathrm{MPa})\end{array}$ \\
\hline 4P-N & 8 & 573.3 & 650.9 \\
& 10 & 519.3 & 634.7 \\
& 12 & 553.8 & 641.8 \\
& 16 & 554.8 & 644.8 \\
\hline 4P-NM & 8 & 550.8 & 648.3 \\
4P-NMM & 10 & 554.8 & 644.4 \\
& 12 & 533.7 & 629.9 \\
& 16 & 550.7 & 650.6 \\
\hline
\end{tabular}

$\varphi:$ diameter of steel reinforcement;

$f_{y}$ : yield strength of reinforcing steel in

tension; $f_{l i}$ : ultimate strength of reinforcing

steel in tension

\section{3. $\quad$ Test setup}

The main purpose of the test setup was to define a loading system able to introduce constant

eccentricity and ensure a well-defined linear distribution of pile reactions for any level of loading. In case of four pile caps the geometric irregularities of the strong floor could affect the aforementioned distribution of reactions, even under a centered load. To avoid this, Clarke [2] introduced the load to the piles with four hydraulic jacks connected via a common manifold to a pump. Suzuki [5-8] also applied the load to the piles but through two hydraulic jacks and two loading beams. For the present tests, some of which required load eccentricity, four independent controlled hydraulic jacks (Fig.6Fig.6) were synchronized to apply a linear distribution of loads to the piles. Perfectly vertical reactions were ensured by means of support devices that up to failure at a constant deformation rate $(0.05 \mathrm{~mm} / \mathrm{s})$.

Con formato: Fuente: 11 pto 


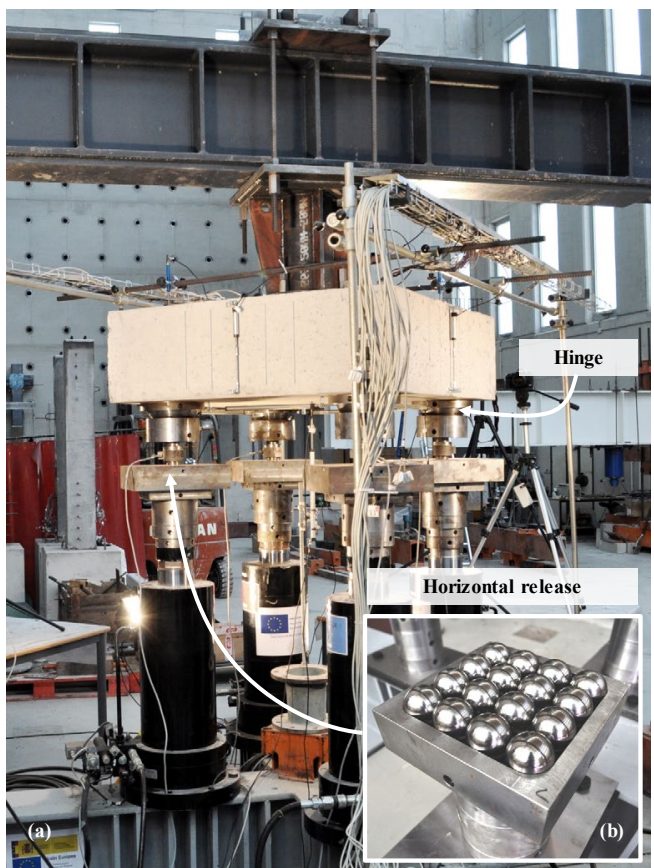

Fig.6 Test setup: (a) General view; (b) Detail of horizontal release

\subsection{Instrumentation}

The load applied through each pile was measured by a load cell (HBM Type C6A 0.5MN) under the hinge. The vertical displacements of the cap soffit were recorded by six displacement transducers (LVDT): one in the centre under the pile cap, one centered on top of the pile cap and four over the piles. Besides, the average strains of bunched and secondary vertical reinforcement were measured by 8-10 LVDT (Fig.4Fig. 4).

A minimum of 32 and maximum of 56 strain gauges were placedset on the rebars to record the strains along the reinforcement versus load.

Seven cameras were synchronized with the data acquisition systems and took one photo per second to plot the evolution of any cracks that appeared on the three sides and lower surface. 


\section{Experimental results and discussion}

Table 7Table 7 summarises the experimental results: the load at which the -bunched reinforcement

Table 7 Summary of the experimental results

\begin{tabular}{llccccccc}
\hline \multicolumn{1}{c}{ Specimen } & $\begin{array}{c}f_{c} / f_{c t} \text { [days] } \\
(\mathrm{MPa})\end{array}$ & $w / d$ & $\begin{array}{c}V_{y, e} \\
(\mathrm{kN})\end{array}$ & $\begin{array}{c}V_{u, e} \\
(\mathrm{kN})\end{array}$ & $\begin{array}{c}R_{u, e} \\
(\mathrm{kN})\end{array}$ & $\begin{array}{c}u_{z} \\
(\mathrm{~mm})\end{array}$ & $\begin{array}{c}\text { Failure } \\
\text { mode }\end{array}$ & $V_{u, e} / V_{y, e}$ \\
\hline 4P-N-A1 & $27.7 / 3.2[98]$ & 1.10 & 581.2 & 613.9 & 153.5 & 4.3 & $\mathrm{p}_{\mathrm{y}}$ & 1.06 \\
4P-N-A2 & $29.5 / 3.1[101]$ & 1.10 & 793.0 & 821.7 & 206.9 & 4.1 & $\mathrm{p}_{\mathrm{y}}$ & 1.04 \\
4P-N-A3 & $30.0 / 3.1[112]$ & 1.10 & 689.7 & 981.5 & 245.7 & 6.6 & $\mathrm{p}_{\mathrm{yw}}$ & 1.42 \\
4P-N-B1 & $26.1 / 3.1[85]$ & 0.74 & 576.5 & 756.2 & 189.1 & 3.3 & $\mathrm{p}_{\mathrm{y}}$ & 1.31 \\
4P-N-B2 & $25.3 / 2.8[88]$ & 0.74 & 569.9 & 872.6 & 219.2 & 3.0 & $\mathrm{p}_{\mathrm{y}}$ & 1.53 \\
4P-N-B3 & $29.9 / 2.2[100]$ & 0.74 & 784.8 & 1127.8 & 281.5 & 7.8 & $\mathrm{p}_{\mathrm{yw}}$ & 1.44 \\
4P-N-C1 & $31.9 / 3.6[27]$ & 0.56 & 739.3 & 957.5 & 233.0 & 9.2 & $\mathrm{f}$ & 1.30 \\
4P-N-C2 & $36.3 / 2.8[23]$ & 0.56 & 960.4 & 1173.9 & 293.0 & 5.7 & $\mathrm{p}_{\mathrm{y}}$ & 1.22 \\
4P-N-C3 & $34.0 / 2.7[21]$ & 0.56 & 1014.1 & 1317.3 & 325.0 & 9.7 & $\mathrm{f}$ & 1.30 \\
4P-NMM-A2 & $36.4 / 3.3[27]$ & 1.10 & 525.1 & 594.5 & 223.9 & 3.8 & $\mathrm{p}_{\mathrm{y}}$ & 1.13 \\
4P-NMM-A3 & $39.2 / 3.8[33]$ & 1.10 & 527.6 & 769.8 & 285.4 & 9.3 & $\mathrm{p}_{\mathrm{yw}}$ & 1.46 \\
4P-NMM-B2 & $39.0 / 3.3[54]$ & 0.74 & 720.1 & 763.2 & 291.8 & 3.2 & $\mathrm{p}_{\mathrm{y}}$ & 1.06 \\
4P-NMM-B3 & $29.9 / 2.7[45]$ & 0.74 & 630.4 & 826.4 & 305.2 & 10.7 & $\mathrm{p}_{\mathrm{yw}}$ & 1.31 \\
4P-NMM-C2 & $30.0 / 3.1[49]$ & 0.56 & 726.1 & 970.1 & 366.8 & 5.6 & $\mathrm{p}_{\mathrm{y}}$ & 1.34 \\
4P-NMM-C3 & $30.5 / 3.2[51]$ & 0.56 & 825.8 & 1076.0 & 409.8 & 9.4 & $\mathrm{f}$ & 1.30 \\
4P-NM-A2 & $27.1 / 3.0[56]$ & 1.10 & 534.7 & 583.7 & 196.3 & 4.3 & $\mathrm{p}_{\mathrm{y}}$ & 1.09 \\
4P-NM-A3 & $30.6 / 3.1[58]$ & 1.10 & 552.4 & 788.1 & 271.1 & 13.8 & $\mathrm{p}_{\mathrm{yw}}$ & 1.43 \\
4P-NM-B2 & $30.2 / 3.0[63]$ & 0.74 & 687.6 & 755.3 & 259.1 & 2.7 & $\mathrm{p}_{\mathrm{y}}$ & 1.10 \\
4P-NM-B3 & $28.1 / 3.0[21]$ & 0.74 & 631.5 & 821.1 & 279.3 & 9.4 & $\mathrm{p}_{\mathrm{y}}$ & 1.30 \\
4P-NM-C2 & $27.9 / 2.8[26]$ & 0.56 & 724.0 & 915.7 & 314.5 & 2.9 & $\mathrm{p}_{\mathrm{y}}$ & 1.26 \\
4P-NM-C3 & $28.8 / 2.7[28]$ & 0.56 & 768.7 & 1004.1 & 342.8 & 15.5 & $\mathrm{f}$ & 1.31 \\
\hline
\end{tabular}

$f_{c:}$ cylinder compressive strength of concrete; $f_{c t}$ axial tensile strength of concrete; $w / d$ : shear span-depth
ratio; $V_{y, e}$ experimental yielding load of the bunched reinforcement; $V_{u e}$ : peak load of tested specimen; $R_{u, e}$ : maximum pile reaction at peak load; $u_{z}$ : vertical displacement of pile at peak load;

Failure mode: f-flexural failure, pyw-punching after yielding of flexural and shear reinforcement,

\subsection{Load-displacement curves}

$3 h$

The load-displacement curves (Fig.7Fig. 7) show a generally brittle response of the pile caps without

vertical stirrups $\mathrm{e}_{2}$ except forexcluding specimen 4P-N-C1 and 4P-NMM-C2. The addition of this reinforcement

to the Type 3 specimens increased their ductility, as can be seen in the slope of the curves. The response of

the pile caps under eccentric loads is similar to that of the caps under axial loads of similar depth and

reinforcement configuration, although they reach higher ultimate pile reactions $\left(R_{u, e}\right)$. 

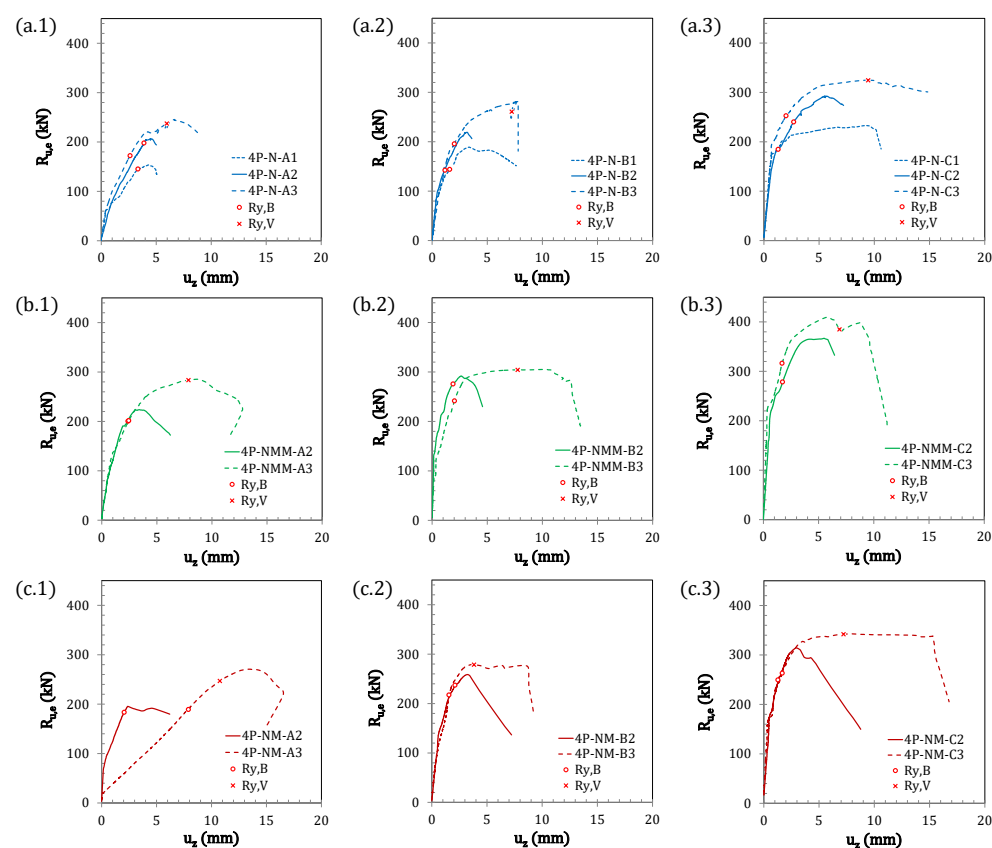

Fig.7 Load-displacement curves: a) Centered load: a.1)4P-N-A; a.2) 4P-N-B; a.3) 4P-N-B; b) Biaxial bending: b.1) 4P-NMM-A b.2) 4P-NMM-B; b.3) 4P-NMM-C; c) Uniaxial bending: c.1) 4P-NM-A (*); c.2) 4P-NM-B; c.3) 4P-NM-C

$\left.{ }^{*}\right)$ Note the large displacements of 4P-NMM-A3 starting the test are attributed-due to a malfunction-wrong data acquisition of the measurement system

Figures 7(a.2) and 7(a.3) show that specimens with type-2 reinforcement layout reach higher peak load •

Con formato: Sangría: Primera línea: $0,75 \mathrm{~cm}$, Interlineado: Doble and display sharper descending branches than those of type-1. This behaviour may be explained in the specimen 4P-N-C2 by the change in the mode of failure: specimen 4P-N-C1 fails in flexure, but the supplementary reinforcement added in specimen 4P-N-C2 increases its flexure resistance more than its punching resistance, so that it fails due to punching. Specimens of the series A and B, the failure is due to punching both for type-1 and type- 2 reinforcement layouts. The larger peak load and lower ductility of specimens of type- 2 are linked to the smaller crack width due to its larger reinforcement areaand. 


\subsection{Failure and yielding load}

Although Fig.7Fig. 7 shows brittle failures in piles caps without vertical reinforcement, the main bounched $_{\star}$ reinforcement yielded in all cases before failure. The pile cap is able to carry further load beyond the yielding point. The lower shear span-depth $(w / d)$, the larger ratio $V_{u, e} / V_{y, e}$ (Table 7Fable 7) is reached in specimens without stirrups. As can be seen, these ratios range from 1.04 to 1.13 for Type A and from 1.22 to 1.34 for Type C. On the other handcontrary, when adding stirrups the higher shear span-depth $(w / d)$, the larger increase in the ratio $V_{u, e} / V_{y, e}(1.42-1.46$ for Type A and 1.30-1.31 for Type C). The values in Table 7Fable 7show higher maximum pile reaction $\left(R_{u, e}\right)$ in the tests with biaxial eccentricity (4P-NMM) than in those with a centered load (4P-N) (8\% to $26 \%)$. However, as expected, the sum of the four reactions $\left(V_{u, e}\right)$ under an eccentric load is lower than under centered loads.

The ultimate load $\left(V_{u, e}\right)$ related to $V_{\text {STM-1 }}($ Table 8Table 8, Fig.5Fig. 5) diminishes with slenderness $(w / d)$, regardless of the type of load and reinforcement configuration. Higher values of the ratio $V_{u, e} / V_{S T M-1}$ are obtained when horizontal and vertical secondary reinforcement are added (Fig.8Fig. 8).

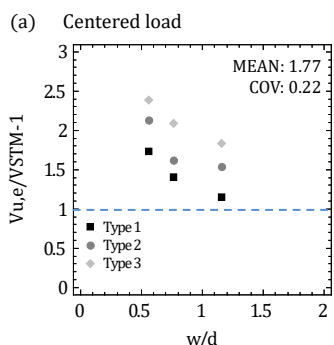

(b) Reinforcement type 2

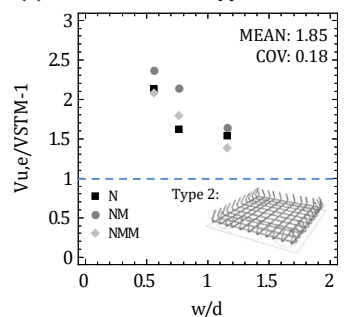

(c) Reinforcement type 3

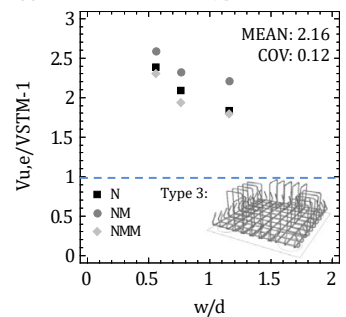

Fig.8 Comparison of experimental to STM failure load prediction (considering $A_{s B}$ to derive the yield strength of the ties): a) Influence of the reinforcement arrangement in specimens tested under centered load; b) Influence of the eccentricity in specimens with reinforcement type 2; c) Influence of the eccentricity in specimens with reinforcement type 3

\subsection{Cracking pattern}

The cracking pattern evolution during the loading process describes the main stress stages. In Fig. 9Fig. 9 the main types of cracks are identified. Initial development of cracks is common in all the tested specimens. First, vertical bending cracks appeared between the piles from each face toward the pile cap soffit centrer. Close to the yielding threshold, some of the vertical cracks near the piles became diagonal. In some cases, typical of Types 2 and 3, when the failure load was reached, fully developed arched cracks were
Con formato: Color de fuente: Rojo

Con formato: Color de fuente: Rojo

Con formato: Fuente: 11 pto

Con formato: Fuente: 11 pto

Con formato: Fuente: 11 pto

Con formato: Fuente: Sin Negrita, Revisar la ortografía y la gramática 
visible ion at least one face. These cracks may indicate the geometry of a potential punching failure surface (Fig.14Fig. 14a). In other cases, typical of Type 1 specimens (4P-N-A1, 4P-N-B1) or symmetrical bending (4P-NM-A2, 4P-NM-B2) ${ }_{2}$ a sudden horizontal crack crossed the bending cracks and caused the failure.

The cracking pattern reveals the influence of load eccentricity (Fig. 2 Fig. 9), pile cap depth (Fig.10Fig. 10), horizontal secondary reinforcement (Fig,11Fig. 11) and vertical secondary reinforcement (Fig,12Fig. 12) on the pile cap response.

Pile caps under eccentric loads showed arched cracks emerging from the piles that reached the maximum reaction, $R_{u, e}$ (Fig. 9 Fig. 9b, c). The load eccentricity enabled longer arches, resulting in a larger failure surface than in those under centered loads.

The deepest pile caps were designed with less reinforcement area to achieve similar flexural strength, and so had comparatively less ratio of longitudinal tension reinforcement $\left(\rho_{l}\right)$. As a consequence, few wide cracks appeared in the Type C pile caps ( (Fig.10Fig. 10a). Adding secondary reinforcement reduced these differences and enabled fully developed arched cracks in the Type B and C specimens (Fig.10Fig. 10e,f) instead of concentrated vertical cracks on the faces. Fig,11Fig. 11 shows the cracking control provided by mesh reinforcement. The effect of horizontal secondary reinforcement on reducing crack width was seen on the underside, regardless of pile cap depth. Vertical secondary reinforcement crossed the arched or suspension cracks of the failure surface (Fig,12Fig. 12) and consequently increased the peak load.

(a)

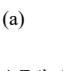
4. Tail of
shear crack shear crack 2. Diag CRACKING LEGEND 二 at peak failure - at peak failure

(a) Centered load, 4P-N-B2 ( $w / d=0.74)$; (b) Biaxial bending, 4P-NMM-B2 ( $w / d=0.74)$; (c) Uniaxial bending, 4P-NM-B2 $(w / d=0.74)$

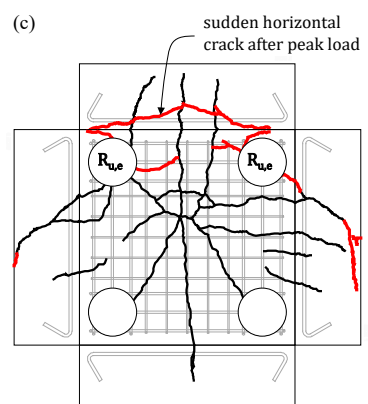

(b)

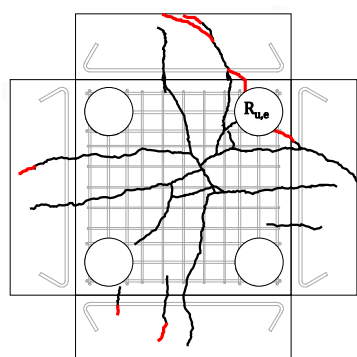
1. Bending crack 12 $\int$
Con formato: Fuente: Sin Negrita, Revisar la ortografía y la gramática

Con formato: Revisar la ortografía y la gramática

Con formato: Revisar la ortografía y la gramática

Con formato: Revisar la ortografía y la gramática

Con formato: Fuente: Sin Negrita, Revisar la ortografía y la gramática

Con formato: Revisar la ortografía y la gramática

Con formato: Revisar la ortografía y la gramática

Con formato: Revisar la ortografía y la gramática

Con formato: Revisar la ortografía y la gramática

Con formato: Revisar la ortografía y la gramática 
(a)

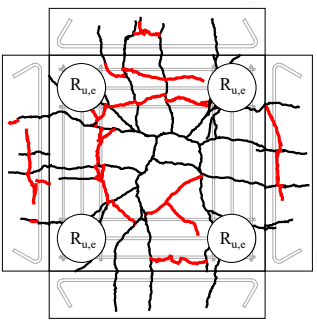

(d)

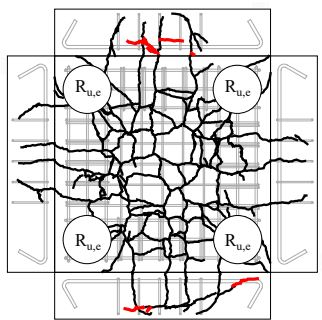

CRACKING LEGEND

— at peak failure (b)
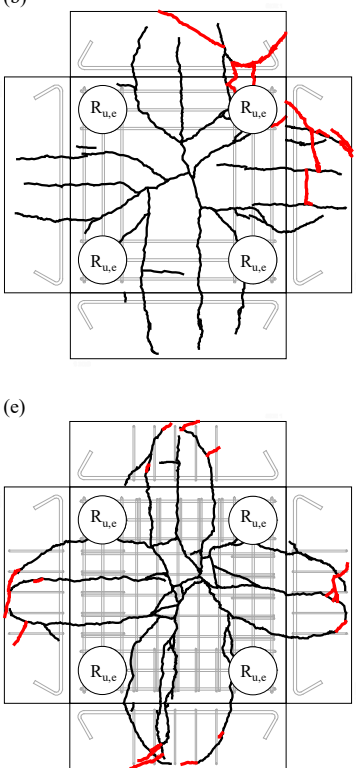

(c)

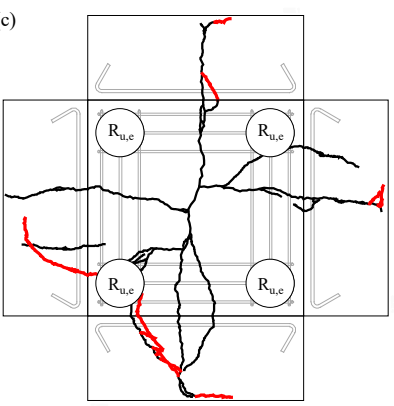

(f)

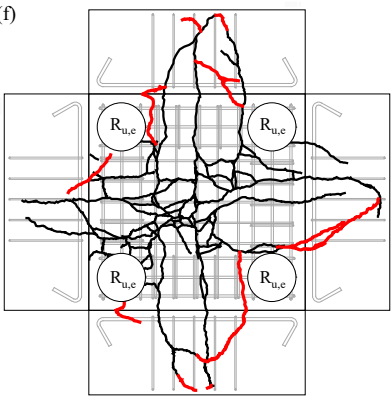

Fig.10 Effect of pile cap depth and secondary reinforcement on the cracking pattern:

(a) 4P-N-A1 ( $w / d=1.10)$; (b) 4P-N-B1 ( $w / d=0.74)$; (c) 4P-N-C1 ( $w / d=0.56)$;(d) 4P-N-A3 ( $w / d=1.10)$; (e) 4P-N-B3 ( $w / d=0.74)$; (f) $4 \mathrm{P}-\mathrm{N}-\mathrm{C} 3(w / d=0.56)$

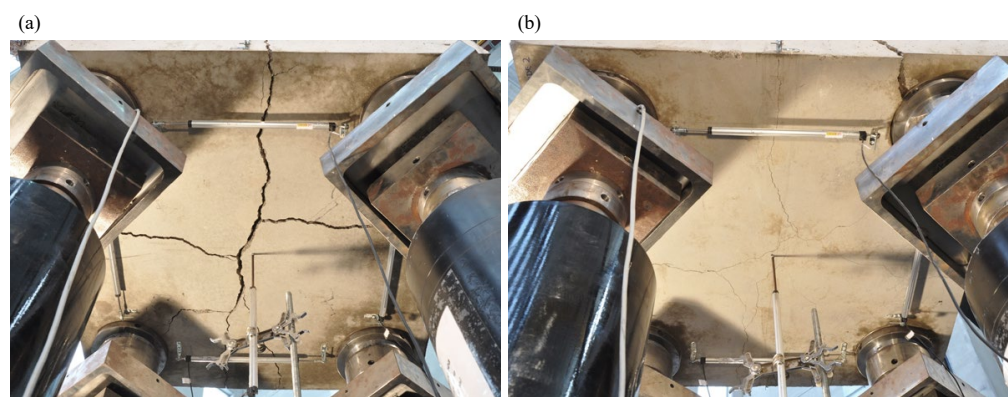

Fig.11 Effect of horizontal secondary reinforcement on the crack width control upon peak load: (a) 4P-N-C1; (b) 4P-N-C2 

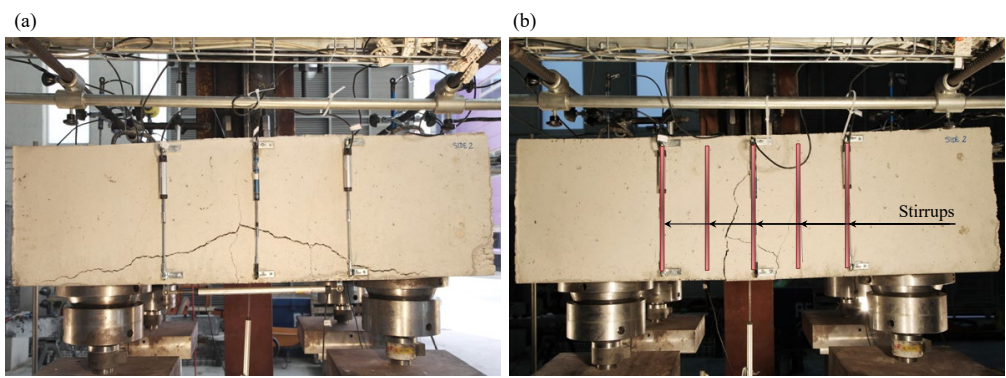

Fig.12 Effect of vertical secondary reinforcement (stirrups) toin resisting vertical thrusts along the sides of pile caps:(a) 4P-NM-B2; (b) $4 \mathrm{P}-\mathrm{NM}-\mathrm{B} 3$

\subsection{Failure mode}

The failure mode of the pile caps was identified from the load-displacement curves (Fig.7) and the evolution of the cracking pattern, following the description shown in Fig.13Fig. 13.

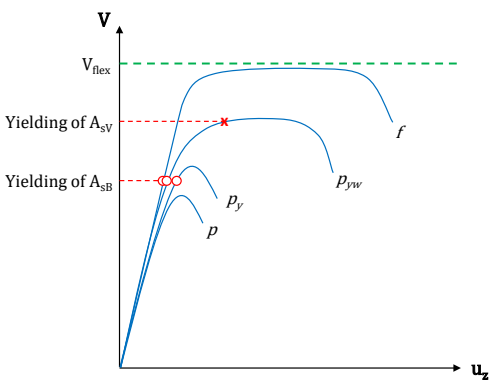

Fig.13 Description of the failure modes based on the load-displacement curves and yielding of reinforcement. Failure legend: $p$-Brittle punching failure without yielding, $p_{y}$-Brittle punching failure with yielding of $A_{s B}$, $p_{y w}$-Ductile punching failure with yielding of both $A_{s B}$ and $A_{s v}$, f-flexural failure

In the Types A and B pile caps without stirrups (A1, A2, B1 and B2) and Types C2, brittle failure occurred after yielding of the main bounched reinforcement ( $p_{y}$ failure in Table 7Table 7) and a punching surface cancould be seen from the cracks on the faces and the final appearance of the pile cap after failure (Fig.14Fig. 14). ItThis is similar to the complex punching surface described in Clarke [2]and Jensen \& Hoang [17].

In the Types A and B specimens with stirrups (A3, B3 except 4P-NM-B3), this reinforcement yieldeds before reaching the maximum load (Fig.7Fig. 7), at which ductile punching failures couldean be seen ( $\mathrm{p}_{\mathrm{yw}}$ failure in Table 7Fable 7). 
(a)

\section{Comparison of experimental results with calculated strength by STM}

The comparison of the experimental results and the ultimate loads predicted by STM were analysed from four different aspects: prediction of the failure mode, the shear span-depth ratio $(w / d)$, the secondary reinforcement, and load eccentricity. To compare the failure loads from the experiments with the predictions, the partial-safety factors $\eta_{\epsilon}-\eta_{s}$ were set as 1.00 .

The three STM proposed in Fig. 5 were used, following the recommendations in the ACI SP-273 [26]. In Fig.8Fig. 8 the experimental results are compared with the STM predictions ( $V_{\text {STM-1 }}$ in Table 8Table 8) without taking into consideration the contribution of the secondary horizontal reinforcement $\left(A_{s H}\right)$ to the capacity of the ties. The predicted results were found to be conservative (MEAN: 1.93) with a coefficient of variation of $20 \%$ (Table 9Table 9). For comparison, the ultimate STM load was also obtained adding the area of the secondary horizontal reinforcement to the ties ( $V_{\text {STM-2in }}$ Table 8 Fable 8$)$, as previously considered in Blévot \& Fremy [1], Clarke [2] and Souza et al. [35]. Also, to indirectly rule out the splitting of the bottle-
Con formato: Color de fuente: Rojo 
shaped struts, compression stress was limited to $0.85 f_{c}$ in the column and pile sections, as indicated in ACI SP-273 [26], although in no case did this restriction capped the load.

\subsection{Failure load and mode of failure prediction}

All the load predictions were found to be safe when compared with the maximum experimental load (MEAN: 1.43, COV: 0.15), but, the safety margin is not the same depending on factors such as slenderness (w/d), the presence of horizontal (Type 2) or vertical (Type 3 ) secondary reinforcement or the eccentricity of load. The influence of these factors is analysed in the sections 6.2 to 6.4.All the load predictions were found to be safe when compared with the maximum experimental load (MEAN: 1.43, COV: 0.15), but, as can be seen in Fig. 15, the influence of factors such as slenderness ( $w / d)$, the presence of horizontal (Type 2) or vertical (Type 3) secondary reinforcement or eccentricity was not captured.
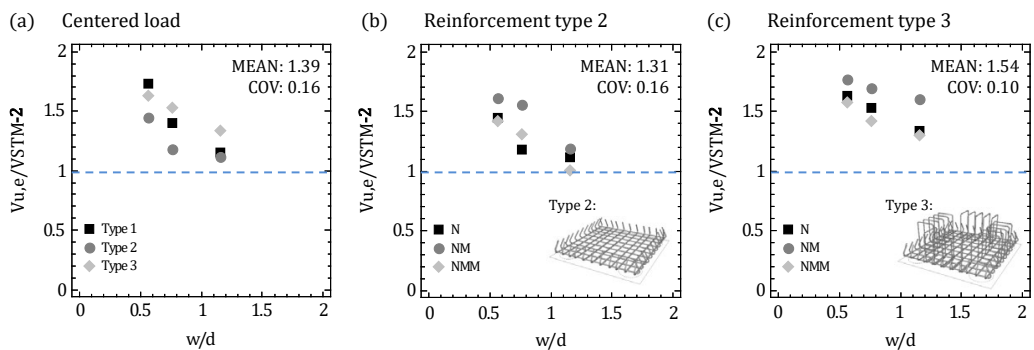

Fig.15 Comparison of experimental to STM failure load prediction (considering $A_{s B}+A_{s H}$ to derive the yield strength of the ties): a) Influence of the reinforcement arrangement in specimens tested under centered load; b) Influence of the eccentricity in specimens with reinforcement type 2; c) Influence of the eccentricity in specimens with reinforcement type 3

Fig.16Fig. 16 shows the comparison of the experimental yielding load ( $V_{y, e}$ in Table 7Table 7) with the STM prediction. The STM explains the beginning of the yielding of the longitudinal reinforcement reasonably well, but since the level arm is fixed it is not able to capture the stress redistribution that would make it possible to increase the load to the point of punching failure observed in most of the pile caps.
Con formato: Sin Resaltar

Con formato: Fuente: 11 pto 


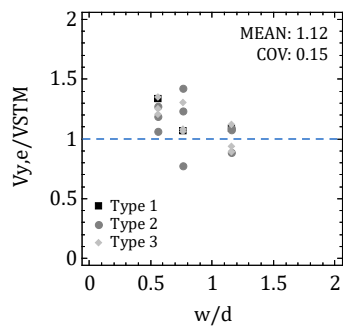

Fig.16Comparison of experimental to STM yielding load prediction

\subsection{Influence of the shear span-depth ratio}

Pile cap slenderness $(w / d)$ influences both the ultimate load and the failure mode observed in the experimental tests, as mentioned in Section 5.2. However, the influence of this variable is not adequately captured with the STM. There is a clear dependence between the experimental-STM failure load ratio and the shear span-depth ratios for all types of load and reinforcement configurations (Fig.15Fig. 15).

\subsection{Influence of the secondary reinforcement}

Fig.15Fig. 15a compares the influence of the reinforcement configuration in specimens tested under centered loads. The ultimate load predictions for pile caps with bunched reinforcement (Type 1: $A_{s B}$ ) were found to be safer than those with secondary horizontal reinforcement (Type 2: $A_{s B}+A_{s H}$ ). In the latter case, half of the secondary reinforcement was considered as part of the tie, but since it was not perfectly anchored beneath the piles, it was not totally effective.

In the specimens with vertical secondary reinforcement (Type 3), as the stirrups are not considered by the STM model, their contribution to the resistance is ignored and the predictions thus obtained are safer than for Type 2. The comparison between Fig.15Fig. 15b and c shows that in the case of eccentric loads adding vertical reinforcement is neithernot taken into account by the STM either and also gives conservative predictions as well.

\subsection{Influence of the load eccentricity}

The influence of eccentric loads applied through the column can be seen in Fig.15Fig. 15b,c. In general the proposed STMs (Fig.5Fig. 5b,c) capture reasonably well variations in pile cap strength when eccentricity 
is added, although the predictions are somewhat more conservative for the specimens loaded by uniaxial bending (NM: $e_{x}=0.15 \mathrm{~m} ; e_{y}=0$ ).

\section{Comparison of experimental results with calculated strength by sectional methods}

The comparison between the experimental results and those predicted by the sectional methods of EC2, ACI 318-14 and MC- 2010 is studied similarly to the STM in Section 6. The capacity to predict the failure load and failure mode is assessed, as well as whether or not the influence of parameters such as slenderness $(w / d)$, secondary reinforcement and eccentricity is captured.

\subsection{Failure load and mode of failure prediction}

The predicted failure load for each code is taken as the minimum $\left(V_{\min -1}\right)$ of the flexural, shear or punching capacity summarized in Table 8Table 8. Although the strength estimated in this way leads to safe predictions (refer to $V_{u, e} / V_{\min -1}$ in Table 9Table 9; EC-2 mean: 1.17, COV: 0.09; ACI 318-14 mean: 1.42, COV: 0.27; MC-2010 mean: 1.31, COV: 0.17), the failure modes predicted by the models do not always match with those experimentally observed (refer to Table 7Table 7).

$\underline{\text { Some codes predict shear failures which were not observed in the tests. Therefore, the predicted loads }}$ were also obtained without considering this type of failure. $\left(V_{\min -2}\right)$. Safe predictions were reached with lower COV than the previous ones (refer to $V_{u, e} / V_{\text {min-2 }}$ in Table 9; EC-2 mean: 1.14, COV: 0.09; ACI 318-14 mean: 1.27, COV: 0.13; MC-2010 mean: 1.26, COV: 0.17).

EC-2 offers the best fit with the actual response obtained, although for its application multiple hypotheses are required $₫ 2,21,22]$ that are not included in the code itself. The formulation proposed in MC2010 fits well with the failure mode described experimentally, although the predictions for the slenderest pile caps $(w / d>1)$ are fairly conservative. Even so, this formulation could be applied without any need to develop additional hypotheses, which would be an advantage for practitioners. ACI 318-14 presents the largest difference between the experimental failure mode-and load prediction, since in most cases it overestimates the punching shear strength of the deepest pile caps $(w / d<1)$ and the flexural capacity is limiting. The formation 2010 fits with

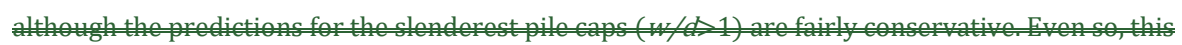

Con formato: Fuente: 11 pto

Con formato: Fuente: 11 pto

\begin{tabular}{|l|}
\hline Con formato: Color de fuente: Rojo \\
\hline Con formato: Color de fuente: Rojo \\
\hline Con formato: Color de fuente: Rojo \\
\hline Con formato: Color de fuente: Rojo \\
\hline
\end{tabular}

Con formato: Color de fuente: Rojo Con formato: Color de fuente: Rojo 


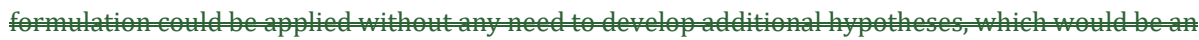

\section{orom}

Since no shear failures were observed in the tests, the predicted loads were also obtained without considering this type of failure $\left(V_{\text {min-2 }}\right)$. Safe predictions were reached with lower COV than the previous ones (refer to $V_{t, t} / V_{\text {min-z }}$ in Table 9; EC-2 mean: 1.14, COV:0.09; ACI 318-14 mean: 1.27, COV: 0.13; MC-2010 mean: 1.26, COV: 0.17).

To analyse the influence of parameters such as slenderness $(w / d)$, secondary reinforcement and eccentric loads in the following sections, the experimental failure mode should be compared with the load predicted by the experimentally observed failure mode ( $V_{u, e} / V_{o b s}$ in $\underline{\text { Table } 9}$ Table 9$)$. The results of this comparison are shown in Fig.17Fig. 17, Fig.18Fig. 18 and Fig.19Fig. 19, for EC-2, ACI 318-14 and MC-2010, respectively.

(a) Centered load

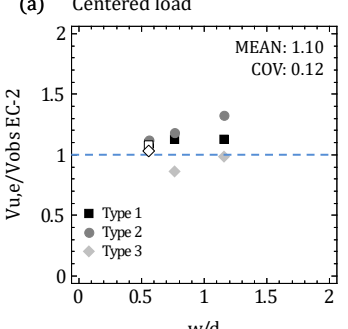

(b) Reinforcement type 2

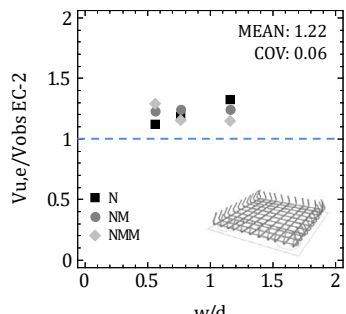

(c) Reinforcement type 3

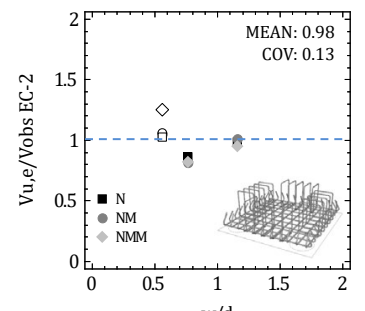

$\diamond$ flexure governing

- - punching governing

Fig.17 EC-2 failure load predictions considering the governing failure mode: a) Influence of the reinforcement arrangement in specimens tested under centered load; b) Influence of the eccentricity in specimens with reinforcement type 2; c) Influence of the eccentricity in specimens with reinforcement type 3
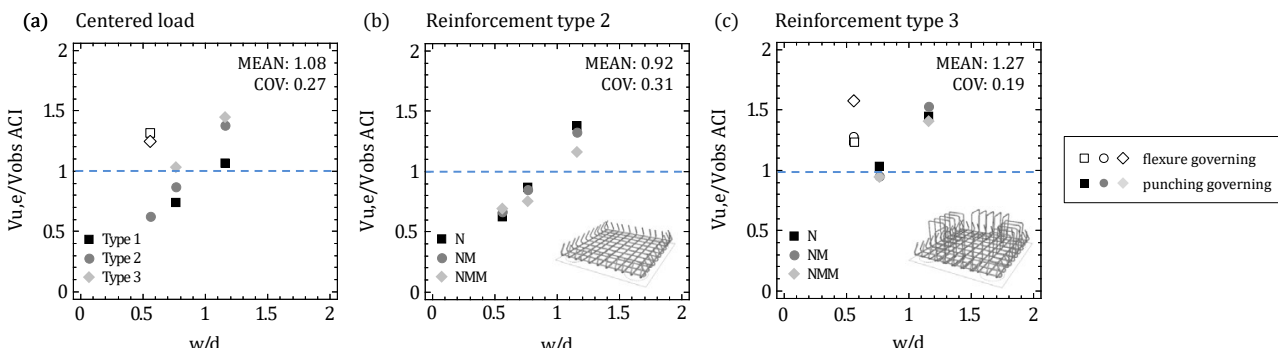

Fig.18 ACI 318-14 failure load predictions considering the governing failure mode: a) Influence of the reinforcement arrangement in specimens tested under centered load; b) Influence of the eccentricity in specimens with reinforcement type 2; c) Influence of the eccentricity in specimens with reinforcement type 3 

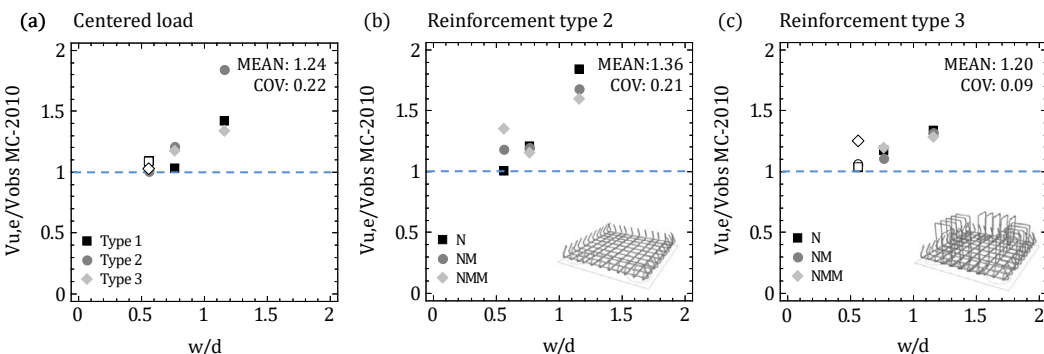

$\square \circ \diamond$ flexure governing

Fig.19 MC-2010 failure load predictions considering the governing failure mode: a) Influence of the reinforcement arrangement in specimens tested under centered load; b) Influence of the eccentricity in specimens with reinforcement type 2; c) Influence of the eccentricity in specimens with reinforcement type 3

\subsection{Influence of the shear span-depth ratio}

The EC-2 punching formulation, after adopting complementary hypotheses $[2,28,29]$, allows for the

effect of slenderness through the enhancement factor ( $\chi$ in Table 2Table 2$)$ applied along the effective width $\left(w_{\text {eff }}\right)$. The effect of this variable is seen to be well reflected in the punching failure load predictions

\section{(Fig.17Fig. 17).}

ACI 318-14 offers an easily applied formulation, but only considers the effect of slenderness $(\chi$ in Table 2Table 2) for very deep pile caps $(w / d<0.5)$. The marked tendency of this variable towards unsafe predictions for the deepest elements can be seen in Fig.18Fig. 18. The CSRI Special Investigation [31]should be revised to include punching of medium slender pile caps $(0.5<w / d \leq 1)$ to improve the brittle failure predictions of these specimens.

MC-2010 (LoAI) allows the slenderness to be considered by means of the ratio $r_{s} / d$, which is included in the calculation of slab rotation $(\psi)$, as part of the punching formulation. Although these predictions are safe, they do not completely capture the influence of the shear span-depth ratio in specimens without stirrups (Fig.19Fig. 19).

\subsection{Influence of the additional secondary horizontal reinforcement}

The formulations considered to determine pile cap flexural capacity $\left(V_{f l e x}\right)$ allow for the contribution of all of the longitudinal reinforcement, and so manage to capture the greater strength of pile caps with secondary horizontal reinforcement (compare flexure governing results in Fig.17Fig. 17, Fig.18Fig. 18 and 

with the experimental failure load .

\section{VeryD different ratios $V_{\underline{u}} / V_{\underline{R d, c s}}$ between the slenderest Type 1 and Type 2 specimens are found in}

Fig.18a. This is because Fthe punching formulation in ACI 318-14 does not allow for the- ratio of longitudinal reinforcement and, as a consequence, it cannot capture the influence of including secondary horizontal

reinforcement. found in Fig. 18 a.

Neither does the punching verification in MC-2010 allow the effect of the ratio of longitudinal reinforcement to be considered at the first level of approximation (LoA1). Higher approximation levels would allow it to be considered by comparing the average bending moment with the design average flexural strength, when calculating the rotation of the element $(\psi)$. A notable difference in the strength predictions can also be detected between the slenderest Type 1 and 2 specimens (Fig.19Fig. 19a).

\subsection{Influence of the shear reinforcement}

EC-2 overestimates the contribution of the stirrups to the punching strength (Fig.17Fig. 17c). The effective shear reinforcement criterion used for slabs ( $\mathrm{A}_{\mathrm{sw}}$ within $75 \%$ of $2 d$ ) is possibly not appropriate for deep pile caps, in which such a flat punching surface is not developed. The ACI 318-14 and MC-2010 formulations only consider effective the stirrups arranged within $1 d$ from the column perimeter, which

ensures safe predictions in all cases (Fig.18Fig. 18c, Fig.19Fig. 19c).

\subsection{Influence of the load eccentricity}

Although each code proposes a different approach to consider eccentricity through the $\beta$ factor indicated in Table 2 Table 2, the predictions for pile caps under eccentric loads follow a similar trend to those tested under centered loads (Fig.17Fig. 17b, c, Fig.18Fig. 18b, c and Fig.19Fig. 19 b, c). That is, i.e. the models properly consider eccentricity, regardless of any variations in the other parameters. 
Table 8 Failure load predicted by the STM and the sectional design methods of EC-2, ACI 318-14 and MC-2010

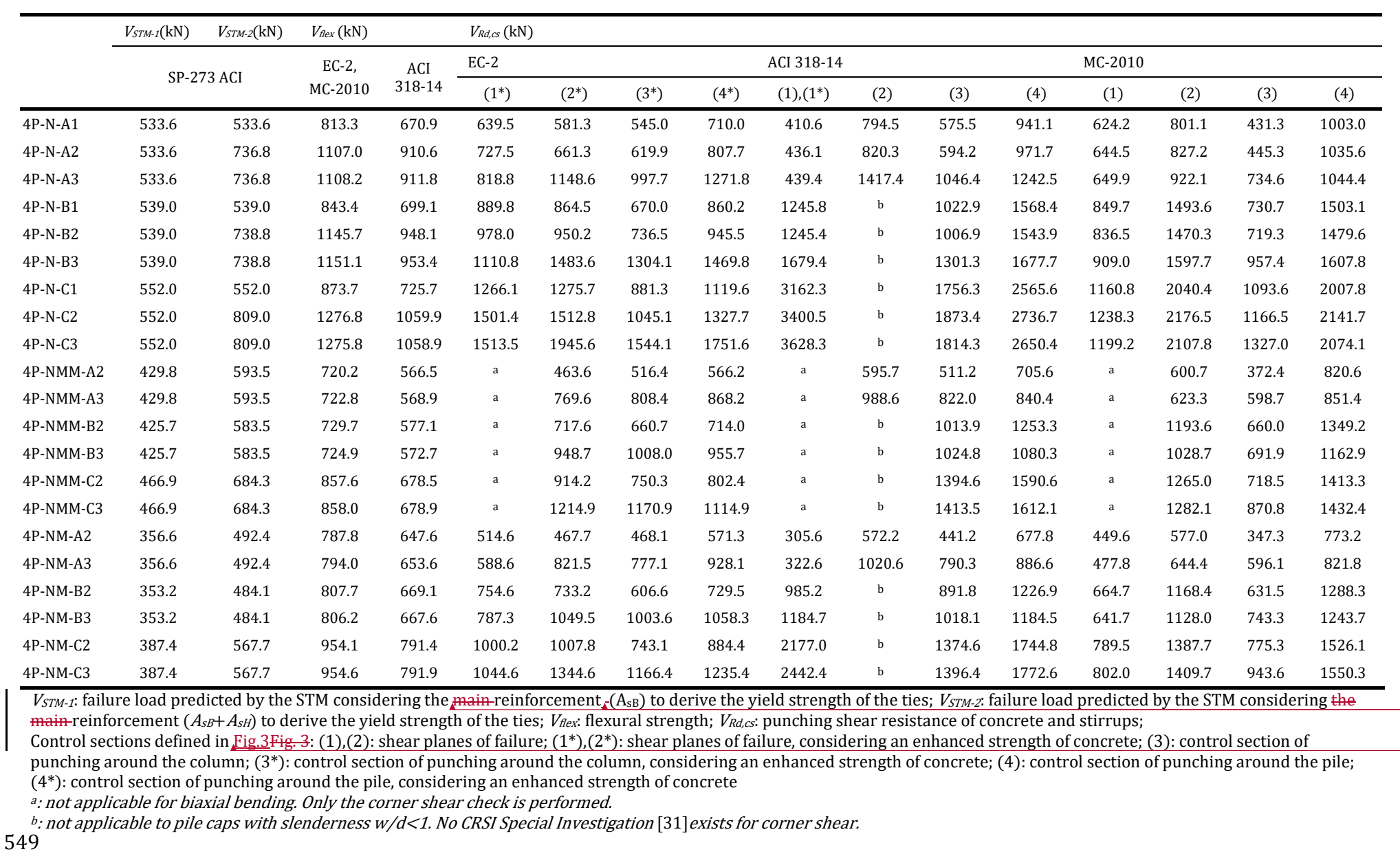

Con formato: Color de fuente: Rojo

Con formato: Color de fuente: Rojo

Con formato: Fuente: 9 pto 
Table 9 Experimental-to-predicted failure load by the STM and sectional design methods

\begin{tabular}{|c|c|c|c|c|c|c|c|c|c|c|c|c|}
\hline & \multirow[t]{2}{*}{$V_{u e,(\mathrm{kN})}$} & \multirow{2}{*}{$\begin{array}{l}V_{u, e} / V_{S T M-1} \\
\text { SP-273 ACI }\end{array}$} & \multirow[t]{2}{*}{$V_{u, e} / V_{S T M-2}$} & \multicolumn{3}{|c|}{$V_{u, e} / V_{\min -1}($ failure mode) } & \multicolumn{3}{|c|}{$V_{u e} / V_{\text {min-2 }}$ (failure mode) } & \multicolumn{3}{|c|}{$V_{u, e} / V_{o b s}$ (failure mode) } \\
\hline & & & & EC-2 & $\begin{array}{l}\text { ACI 318- } \\
14\end{array}$ & MC-2010 & EC-2 & $\begin{array}{l}\text { ACI 318- } \\
14\end{array}$ & MC-2010 & EC-2 & $\begin{array}{l}\text { ACI 318- } \\
14\end{array}$ & MC-2010 \\
\hline 4P-N-A1 & 613.9 & 1.15 & 1.15 & $1.13\left(3^{*}\right)$ & $1.50(1)$ & $1.42(3)$ & $1.13\left(3^{*}\right)$ & $1.07(3)$ & $1.42(3)$ & $1.13\left(3^{*}\right)$ & $1.07(3)$ & $1.42(3)$ \\
\hline $4 \mathrm{P}-\mathrm{N}-\mathrm{A} 2$ & 821.7 & 1.54 & 1.12 & $1.33\left(3^{*}\right)$ & $1.88(1)$ & $1.85(3)$ & $1.33\left(3^{*}\right)$ & $1.38(3)$ & $1.85(3)$ & $1.33\left(3^{*}\right)$ & $1.38(3)$ & $1.85(3)$ \\
\hline 4P-N-A3 & 981.5 & 1.84 & 1.33 & $1.20\left(1^{*}\right)$ & $2.23(1)$ & $1.51(1)$ & $0.98\left(3^{*}\right)$ & $1.45(3)$ & $1.34(3)$ & $0.98\left(3^{*}\right)$ & $1.45(3)$ & $1.34(3)$ \\
\hline 4P-N-B1 & 756.2 & 1.40 & 1.40 & $1.13\left(3^{*}\right)$ & $1.08(f)$ & $1.03(3)$ & $1.13\left(3^{*}\right)$ & $0.74(\mathrm{f})$ & $1.03(3)$ & $1.13\left(3^{*}\right)$ & $0.74(3)$ & $1.03(3)$ \\
\hline 4P-N-B2 & 872.6 & 1.62 & 1.18 & $1.18\left(3^{*}\right)$ & $0.92(\mathrm{f})$ & $1.21(3)$ & $1.18\left(3^{*}\right)$ & $0.87(\mathrm{f})$ & $1.21(3)$ & $1.18\left(3^{*}\right)$ & $0.87(3)$ & $1.21(3)$ \\
\hline $4 \mathrm{P}-\mathrm{N}-\mathrm{B} 3$ & 1127.8 & 2.09 & 1.53 & $1.02\left(1^{*}\right)$ & $1.18(\mathrm{f})$ & $1.24(1)$ & $0.98(\mathrm{f})$ & $1.03(\mathrm{f})$ & $1.18(3)$ & $0.86\left(3^{*}\right)$ & $1.03(3)$ & $1.18(3)$ \\
\hline $4 \mathrm{P}-\mathrm{N}-\mathrm{C} 1$ & 957.5 & 1.73 & 1.73 & $1.10(\mathrm{f})$ & $1.32(\mathrm{f})$ & $1.10(\mathrm{f})$ & $1.10(\mathrm{f})$ & $1.32(\mathrm{f})$ & $1.10(\mathrm{f})$ & $1.10(\mathrm{f})$ & $1.32(\mathrm{f})$ & $1.10(\mathrm{f})$ \\
\hline $4 \mathrm{P}-\mathrm{N}-\mathrm{C} 2$ & 1173.9 & 2.13 & 1.45 & $1.12\left(3^{*}\right)$ & $1.11(\mathrm{f})$ & $1.01(3)$ & $1.12\left(3^{*}\right)$ & $0.63(\mathrm{f})$ & $1.01(3)$ & $1.12\left(3^{*}\right)$ & $0.63(3)$ & $1.01(3)$ \\
\hline $4 \mathrm{P}-\mathrm{N}-\mathrm{C} 3$ & 1317.3 & 2.39 & 1.63 & $1.03(\mathrm{f})$ & $1.24(\mathrm{f})$ & $1.10(1)$ & $1.03(\mathrm{f})$ & $1.24(\mathrm{f})$ & $1.03(\mathrm{f})$ & $1.03(\mathrm{f})$ & $1.24(\mathrm{f})$ & $1.03(\mathrm{f})$ \\
\hline 4P-NMM-A2 & 594.5 & 1.38 & 1.00 & $1.28\left(2^{*}\right)$ & $1.16(3)$ & $1.60(3)$ & $1.15\left(3^{*}\right)$ & $1.16(3)$ & $1.60(3)$ & $1.15\left(3^{*}\right)$ & $1.16(3)$ & $1.60(3)$ \\
\hline 4P-NMM-A3 & 769.8 & 1.79 & 1.30 & $1.07(\mathrm{f})$ & 1.35 (f) & $1.29(3)$ & $1.07(\mathrm{f})$ & $1.41(3)$ & $1.29(3)$ & $0.95\left(3^{*}\right)$ & $1.41(3)$ & $1.29(3)$ \\
\hline 4P-NMM-B2 & 763.2 & 1.79 & 1.31 & $1.16\left(3^{*}\right)$ & $1.32(f)$ & $1.16(3)$ & $1.16\left(3^{*}\right)$ & 0.75 (f) & $1.16(3)$ & $1.16\left(3^{*}\right)$ & $0.75(3)$ & $1.16(3)$ \\
\hline 4P-NMM-B3 & 826.4 & 1.94 & 1.42 & $1.14(\mathrm{f})$ & $1.44(\mathrm{f})$ & $1.19(3)$ & $1.14(\mathrm{f})$ & 0.95 (f) & $1.19(3)$ & $0.86\left(4^{*}\right)$ & $0.95(3)$ & $1.19(3)$ \\
\hline 4P-NMM-C2 & 970.1 & 2.08 & 1.42 & $1.29\left(3^{*}\right)$ & $1.43(\mathrm{f})$ & $1.35(3)$ & $1.29\left(3^{*}\right)$ & 0.70 (f) & $1.35(3)$ & $1.29\left(3^{*}\right)$ & $0.70(3)$ & $1.35(3)$ \\
\hline 4P-NMM-C3 & 1076.0 & 2.30 & 1.57 & $1.25(\mathrm{f})$ & $1.58(\mathrm{f})$ & $1.25(\mathrm{f})$ & $1.25(\mathrm{f})$ & 1.59 (f) & $1.25(\mathrm{f})$ & $1.25(\mathrm{f})$ & 1.59 (f) & $1.25(\mathrm{f})$ \\
\hline 4P-NM-A2 & 583.7 & 1.64 & 1.19 & $1.25\left(2^{*}\right)$ & $1.91(1)$ & $1.68(3)$ & $1.25\left(3^{*}\right)$ & $1.32(3)$ & $1.68(3)$ & $1.25\left(3^{*}\right)$ & $1.32(3)$ & $1.68(3)$ \\
\hline 4P-NM-A3 & 788.1 & 2.21 & 1.60 & $1.34\left(1^{*}\right)$ & $2.44(1)$ & $1.65(1)$ & $1.01\left(3^{*}\right)$ & $1.53(3)$ & $1.32(3)$ & $1.01\left(3^{*}\right)$ & $1.53(3)$ & $1.32(3)$ \\
\hline 4P-NM-B2 & 755.3 & 2.14 & 1.56 & $1.25\left(3^{*}\right)$ & $1.13(\mathrm{f})$ & $1.20(3)$ & $1.25\left(3^{*}\right)$ & 0.85 (f) & $1.20(3)$ & $1.25\left(3^{*}\right)$ & $0.85(3)$ & $1.20(3)$ \\
\hline 4P-NM-B3 & 821.1 & 2.32 & 1.70 & $1.04\left(1^{*}\right)$ & $1.23(\mathrm{f})$ & $1.28(1)$ & $1.02(\mathrm{f})$ & $0.95(\mathrm{f})$ & $1.10(3)$ & $0.82\left(3^{*}\right)$ & $0.95(3)$ & $1.10(3)$ \\
\hline 4P-NM-C2 & 915.7 & 2.36 & 1.61 & $1.23\left(3^{*}\right)$ & $1.16(\mathrm{f})$ & $1.18(3)$ & $1.23\left(3^{*}\right)$ & 0.67 (f) & $1.18(3)$ & $1.23\left(3^{*}\right)$ & $0.67(3)$ & $1.18(3)$ \\
\hline \multirow[t]{3}{*}{ 4P-NM-C3 } & 1004.1 & 2.59 & 1.77 & $1.05(\mathrm{f})$ & $1.27(\mathrm{f})$ & $1.25(1)$ & $1.05(\mathrm{f})$ & $1.27(\mathrm{f})$ & $1.06(3)$ & $1.05(\mathrm{f})$ & $1.27(\mathrm{f})$ & $1.05(\mathrm{f})$ \\
\hline & MEAN & 1.93 & 1.43 & 1.17 & 1.42 & 1.31 & 1.14 & 1.27 & 1.26 & 1.10 & 1.09 & 1.26 \\
\hline & cov & 0.20 & 0.15 & 0.09 & 0.27 & 0.17 & 0.09 & 0.13 & 0.17 & 0.13 & 0.28 & 0.17 \\
\hline
\end{tabular}

$V_{u, e:}$ experimental failure load at column; $V_{S T M-1:}$ failure load predicted by the STM considering the main reinforcement (AsB) to derive the yield strength of the ties; $V_{S T M-2:}$ failure load predicted by the STM considering the main reinforcement $\left(\mathrm{A}_{\mathrm{sB}}+\mathrm{A}_{\mathrm{sH}}\right)$ to derive the yield strength of the ties; $V_{\text {min-1: }}$ minimum resistance predicted by the codes; $V_{\min -2:}$ minimum resistance predicted by the codes excluding shear failures; VOBS: resistance predicted by the codes according to the observed mode of failure;

Control sections defined in Fig.3Fig. 3: (1),(2): shear planes of failure; $\left(1^{*}\right),\left(2^{*}\right)$ : shear planes of failure, considering an enhanced strength of concrete; (3): control section of punching around the column; $\left(3^{*}\right)$ : control section of punching around the column, considering an enhanced strength of concrete; (4): control section of punching around the pile; $\left(4^{*}\right)$ : control section of punching around the pile, considering an 


\section{Conclusions}

This paper describes an experimental campaign with 21 four-pile caps to study the influence of eccentric loads, slenderness and secondary reinforcement. The main conclusions drawn from these experiments are as follows:

1. Most pile caps without vertical secondary reinforcement showed brittle failures after yielding of the bunched reinforcement, with clear evidence of a punching failure surface. The presence of vertical reinforcement (stirrups) increases the ductility and the maximum loadMost pile caps without vertical secondary reinforcement showed brittle failures after yielding of the bunched reinforcement, with clear evidence of a punching failure surface.

2. In pile caps with the same design load according to STM, the failure load decreased as slenderness (w/d) increased.

3.2.-As expected, The the presence of horizontal secondary reinforcement reduces cracking in the base and improves pile cap strength.

4. The presence of vertical secondary reinforcement (stirrups) also increases the maximum load and improves the ductility of the element.

5.3. When eccentric loads are applied to the column, the maximum pile reaction at failure is greaterlarger than that reached without eccentricity. The observed increase has been up to $26 \%$ the ultimate load is reduced but the maximum pile reaction is increased by up to $26 \%$.

6.4.Under eccentric loads the influence of slenderness and the contribution of the secondary reinforcement are similar to the case of centered loads.

The experimental results were used to compare the pile cap design methods accepted by codes EC-2, ACI 318-14 and MC-2010: strut-and-tie models and the sectional approach. The conclusions reached from this comparison are as follows:

7.5.STM provide a lower bound of the pile cap strength (mean: 1.43, COV: 0.15 ), but the higher spandepth ratio $(w / d)$ the lower safety margin. Usual strut-and-tie models allows to consider eccentric loads without losing safety margin, but nevertheless they cannot capture the contribution of the vertical secondary reinforcement. The presence of horizontal secondary reinforcement can be 
considered as part of the ties, but an efficiency factor less than one should be applied.STM provides a lower bound of the pile cap strength (mean: $1.43, \mathrm{COV}: 0.15$ ), although it is not possible to predict the failure mode after yielding of ties. Neither do they adequately capture the influence of the slenderness or the presence of vertical secondary reinforcement. On the other hand, STM are able to consider eccentric loads, including tension forcestransmitted from the column. . to safe failure load predictions (EC-2 mean: 1.17, COV: 0.09; ACI 318-14 mean: 1.42, COV: 0.27; MC2010 mean: 1.31, COV: 0.17), although the limiting failure modes do not always match with those experimentally observed. Comparisons without including shear failure modes are also safe and come closer to the experimental results (EC-2 mean: 1.14, COV: 0.09; ACI 318-14 mean: 1.27, COV: 0.13; MC-2010 mean: 1.26, COV: 0.17).

9.-When the flexural capacity is limiting, the ACI 318-14 formulation is more conservative than EC-2 and MC-2010 due to the control section being at c/4 away from the column centerline.

10.7. When failure is due to punching all the codes properly capture the influence of load eccentricity.

11.8. EC-2 requires multiple hypotheses to apply its punching formulation to pile caps, such as considering the enhancement of an effective width of concrete [2]. Comparison with the experimental tests confirms that the enhancement factor is efficient to capture the effect of slenderness on punching failures (Fig.17Fig. 17). The EC-2 formulation allows adequate consideration of the horizontal secondary reinforcement on strength through the ratio of longitudinal tension reinforcement $\left(\rho_{l}\right)$. However, EC-2 overestimates the contribution of the stirrups to the punching strength, leading to the unsafe predictions in some specimens are slightly unsafe when the contribution of the punching reinforcement is considered.:

12.9. ACI 318-14 includes a specific punching shear formulation [31] for the deepest pile caps and thus does not require the designer to adopt additional hypotheses. Although this is a big advantage, in the case of medium-slender pile caps $(0.5<w / d<1)$ the influence of the shear span-depth ratio is not adequately captured and the strength of the deepest is overestimated (Fig.18Fig. 18). The ACI 
318-14 formulation does not consider the influence of the ratio of longitudinal tension reinforcement in the strength, which has indeed been found experimentally relevant. The secondary vertical reinforcement can be considered as punching reinforcement, although only the stirrups arranged inside the effective depth from the perimeter of the column are considered effective.

10. The MC-2010 punching formulation can be directly applied to deep pile caps, although it is limited to elements with slenderness $(w / d)$ greater than 0.5 . With LoAI, the influence of the slenderness and the ratio of longitudinal tension reinforcement is not completely captured, although it fulfils the requirements for this level of approximation: to provide a simple and safe tool to assess the punching strength of the pile caps (Fig.19Fig. 19). The use of more accurate levels of approximation could improve the consideration of both these factors and will be the subject of future research for experimental comparison. The effective contribution of punching reinforcement is well defined (between $0.35 d_{v}$ and $d_{v}$ from the column perimeter) and offers safe predictions.

13. Further experimental investigation is needed to extend these conclusions to pile caps with other conditions than those of the experimental campaign carried out in this work.

\section{Acknowledgments}

The authors wish to express their gratitude for the financial support (BIA2012-32300 and BIA2015-

64672-C4-4-R) received from the Spanish Ministry of Economy and Competitiveness, which enabled to carry out the experimental campaign to be carried out, also for the PhD fellowship (BES-2013-063409). 


\section{References}

[1] Blevot J, Frêmy R. Semelles sur pieux. Ann l'Institut Tech Du Bâtiment Des Trav Publics 1967;20:223-95.

[2] Clarke JL. Behaviour and design of pile caps with four pile caps. Cem Concr Assoc 1973.

[3] Gogate AB, Sabnis GM. Design of thick pile caps. ACI J 1980;77:18-22.

[4] Adebar P, Kuchma D, Collins MP. Strut-and-tie models for the design of pile caps: an experimental study. ACI Struct J 1990;87:81-92.

[5] Suzuki K, Otsuki K, Tsubata T. Influence of bar arrangement on ultimate strength of four-pile caps. Trans Japan Concr Inst 1998;20:195-202.

[6] Suzuki K, Otsuki K, Tsubata T. Experimental Study on Four Pile Caps with Taper. Trans Japan Concr Inst 1999;21:327-34.

[7] Suzuki K, Otsuki K, Tsuchiya T. Influence of Edge Distance on Failure Mechanisms of Pile Caps. Trans Japan Concr Inst $2000 ; 22: 361-8$

[8] Suzuki K, Otsuki K. Experimental study on corner shear failure of pile caps. Trans Japan Concr Inst 2002;23:303-10

[9] Bloodworth AG, Jackson PA, Lee MMK. Strength of reinforced concrete pile caps. Proc Inst Civ Eng - Struct Build 2003;156:347-58.

[10] Miguel MG, Takeya T, Giongo JS. Structural behaviour of three-pile caps subjected to axial compressive loading. Mater Struct 2008;41:85-98. doi:10.1617/s11527-007-9221-5.

[11] Delalibera RG, Giongo JS. Deformations in the strut of two pile caps. Rev IBRACON Estruturas E Mater 2008;1:121-57. doi:10.1590/S1983-41952008000200002.

[12] Gu Q, Sun CF, Peng SM. Experimental Study on Deep Four-Pile Caps with Different Reinforcement Layouts Based on 3D Strutand-Tie Analogy. Key Eng Mater 2009;400-402:917-22. doi:10.4028.

[13] Adebar P, Zhou Z. Design of deep pile caps by strut-and-tie models. ACI Struct J 1996;93:437-48.

[14] Guo H. Evaluation of column load for generally uniform grid-reinforced pile cap failing in punching. ACI Struct J $2015 ; 112$. doi:10.14359/51687420.

[15] Miguel-Tortola L, Pallarés L, Miguel PF. Punching shear failure in three-pile caps: Influence of the shear span-depth ratio and secondary reinforcement. Eng Struct 2018;155:127-43. doi:10.1016/j.engstruct.2017.10.077.

[16] Souza R, Kuchma D, Park J, Bittencourt T. Nonlinear finite element analysis of four pile-caps supporting columns subjected to generic loading. Comput Concr 2007;4:363-76.

[17] Jensen UG, Hoang LC. Collapse mechanisms and strength prediction of reinforced concrete pile caps. Eng Struct 2012;35:203-14. doi:10.1016/j.engstruct.2011.11.006.

[18] Simões JT, Faria DM V, Muttoni A, Fernández Ruiz M. Limit Analysis for Punching Shear Design of Compact Slabs and Footings. fib Symp., Copenhagen, Denmark: 2015, p. 13.

[19] ACI Committee 318. Building Code Requirements for Reinforced Concrete and Commentary (ACI 318-14/ACI 318S-14). American Concrete Institute; 2014

[20] CEN. Eurocode 2: Design of concrete structures - Part 1-1: General rules and rules for buildings; Spanish version UNE-EN1992-1-1:2004. 2013.

[21] Hendy CR, Smith DA. Designers' Guide to EN 1992-2. London: Thomas Telford; 2007.

[22] Bond AJ, Brooker O, Harris AJ, Harrison T, Moss RM, Narayanan RS, et al. How to Design Concrete Structures using Eurocode 2. Camberley: The Concrete Centre; 2006 .

[23] Mays TW. Design Guide for Pile Caps. Concrete Reinforcing Steel Institute; 2015.

[24] FIB. Design examples for strut-and-tie models. fib Bulletin 61. 2011.

[25] ACHE Comisión 1. Monografia M6 Método de Bielas y Tirantes (in Spanish). 2003.

[26] ACI. SP-273 Further Examples for the Design of Structural Concrete with Strut-and-Tie Models. 2011.

[27] Fédération Internationale du Béton (fib). Model Code 2010, final drafts (Vol. 2). Lausanne, Switzerland: 2012.

Con formato: Alemán (Alemania)

[28] Subcommittee B/525/2. BS 8110-1:1997 Structural use of Concrete. Part 1: Code of practice for design and construction. British Standard Institution; 1997.

[29] Technical Committee CSB/30. BS 5400-4: 1990 Steel, concrete and composite bridges - Part 4: Code of practice for design of concrete bridges. British Standard Institution; 1990.

[30] Hanson NW, Hanson JM. Shear and Moment Transfer Between Concrete Slabs and Columns. J Portl Cem Assoc 1968;10:2-16. 
[31] Committe on Design Aids. CRSI Handbook, 10th Edition. Schaumburg, IL: Concrete Reinforcing Steel Institute; 2008.

[32] Muttoni A, Schwartz J. Behaviour of Beams and Punching in Slabs without Shear Reinforcement. IABSE Reports 1991;62:703-8.

[33] Vaz Rodrigues R. Shear strength of reinforced concrete bridge deck slabs. PhD Thesis. Ecole Polytechnique Fédérale de Lausanne, Lausanne, Switzerland, 2007.

[34] CEN. UNE-EN ISO 15630-1 Steel for the reinforcement and prestressing of concrete. Test methods. Part 1: Reinforcing bars, wire rod and wire. 2010.

[35] Souza R, Kuchma D, Park J, Bittencourt T. Adaptable Strut and Tie Model for Design and Verfication of four pile caps. ACI Struct J 2009;106:142-50. 